\author{
Universidade de São Paulo \\ Faculdade de Medicina de Ribeirão Preto \\ Departamento de Farmacologia
}

ROSE INÊS MATOS BATISTA

Enxaguante bucal inibe os efeitos anti-hipertensivos da L-arginina em modelo de hipertensão 2R1C.

Ribeirão Preto - SP 


\section{Enxaguante bucal inibe os efeitos anti-hipertensivos da L-arginina em modelo de hipertensão 2R1C.}

Dissertação apresentada à Faculdade de Medicina de Ribeirão Preto da Universidade de São Paulo para obtenção do título de Mestre em Ciências.

Área de concentração: Farmacologia

Orientador: Prof. Dr. José Eduardo Tanus dos Santos

Ribeirão Preto - SP 


\begin{abstract}
AUTORIZO A REPRODUÇÃO TOTAL OU PARCIAL DESTE TRABALHO, POR QUALQUER MEIO CONVENCIONAL OU ELETRÔNICO, PARA FINS DE ESTUDO E PESQUISA, DESDE QUE CITADA A FONTE.
\end{abstract}

FICHA CATALOGRÁFICA

Batista, Rose Inês Matos

Enxaguante bucal inibe os efeitos anti-hipertensivos da Larginina em modelo de hipertensão 2R1C. Rose Inês Matos Batista; Orientador: Prof. Dr. José Eduardo Tanus dos Santos. Ribeirão Preto, 2019. 64f.

Dissertação (Mestrado em Ciências - Área de Concentração: Farmacologia - Faculdade de Medicina de Ribeirão Preto da Universidade de São Paulo.

1. L-arginina. 2. Enxaguante bucal 3. Ciclo êntero-salivar do nitrato, 4. Efeitos vasculares 5. Efeitos anti-hipertensivos 
Dedico este trabalho a toda a minha família, que sempre esteve e sempre vai estar ao meu lado:

Minha mãe Regina, você é a maior responsável pela pessoa que me tornei.

Meu pai Ribamar, pelo esforço incansável em propiciar prover tudo o que foi necessário para que eu chegasse até aqui.

Amo todos você. 


\section{AGRADECIMENTOS}

Em primeiro lugar quero agradecer a Deus por todas as coisas boas e ruins que me aconteceram. Cada uma delas, ao seu modo, me fizeram chegar onde cheguei.

À toda minha família, em especial aos meus queridos pais por tudo aquilo de que abdicaram para que esse sonho se tornasse realidade e às minhas irmãs Rosa $e$ Regiane, por toda a cumplicidade e amor na vida que compartilhamos desde sempre e ao meu sobrinho, Henrique que, em seus quase 2 anos de vida, é a pessoa que mais coloca sorriso na boca de todos. Essa conquista é tão de vocês quanto minha.

Ao meu orientador, professor José Eduardo Tanus dos Santos, pela oportunidade, confiança e apoio na elaboração deste trabalho e por me ensinar todos os dias um pouco sobre o que é ser pesquisadora.

Aos meus colaboradores, Renato, Graziele, Gustavo, Célio, Lucas e Evandro, que nunca mediram esforços para me ajudar na execução de nenhuma etapa do trabalho. Um agradecimento especial à Grazi, ao Célio, ao Gustavo e ao Evandro a quem eu devo quase todas as técnicas que aprendi no laboratório.

À Sandra pelo excelente apoio técnico e por sempre nos "salvar" nas horas mais desesperadoras e também pela grande amizade dentro e fora do laboratório. Afinal, o que seria de nós sem você?

Aos meus demais colegas de laboratório, Indiara, Danielle, Jéssica, Tiago, Leevan, Jefferson, Juliana, Ana Laura, obrigada pela ótima convivência e por toda a amizade e companheirismo.

Aos professores, funcionários e colegas do departamento de Farmacologia, em especial ao Ramon e a Gislaine por estarem sempre dispostos a tirar toda e qualquer dúvida.

Um agradecimento especial ao Renato, por dividir uma casa, um laboratório, enfim, todo esse sonho comigo e também por me ajudar a encarar a realidade e os momentos difíceis sempre com muito bom humor e à Grazi e à Indiara, por serem as melhores amigas de lab que alguém poderia ter.

Ao Valter, por todo o amor e compreensão nesses dois anos de muita crise existencial. Obrigada por tudo mesmo.

Aos meus amigos da faculdade Bianca, Lisandra, Lorena, Paulo por terem me apoiado sempre que precisei. Vocês sempre terão um lugar cativo no meu coração. Sinto muita saudade.

Às minhas amigas de infância Aline, Nayanne e Letícia, por, mesmo de longe sempre estarem torcendo por mim e vibrando com todas as minhas conquistas.

Ao CNPq e a FAPESP pelo apoio financeiro. 


\section{RESUMO}

BATISTA, R.I.M. Enxaguante bucal inibe os efeitos anti-hipertensivos da Larginina em modelo de hipertensão 2R1C. 2019. 65f. Dissertação (Mestrado) Faculdade de Medicina de Ribeirão Preto, Universidade de São Paulo, Ribeirão Preto, 2019.

Introdução: O óxido nítrico (NO) é produzido pela ação das óxido nítrico sintases (NOS), possuindo como único substrato para essa produção o aminoácido L-arginina. Além dessa via, a biodisponibilidade de NO também pode ser aumentada pelo ciclo êntero-salivar do nitrato, no qual a presença de bactérias orais com capacidade nitrato redutase é limitante. Assim, a hipótese deste trabalho é de que o enxaguante bucal pode atenuar os efeitos benéficos da L-arginina na hipertensão. Métodos: Ratos Hannover foram divididos em 4 grupos Sham e 4 grupos 2 rins 1 clipe (2R1C) com os tratamentos Veículo (água), Enxaguante bucal, L-arginina e L-arginina + Enxaguante bucal. $O$ tratamento com L-arginina foi feito na água de beber em uma concentração de $10 \mathrm{~g} / \mathrm{L}$ e o enxaguante bucal foi aplicado na mucosa oral com o auxílio de um swab. A pressão sistólica foi monitorada semanalmente e ao final das 4 semanas de tratamento, todos os animais foram submetidos a análise da atividade nitrato redutase das bactérias orais, além de reatividade de aorta e coleta de plasma e aorta para análises bioquímicas. Todos os procedimentos foram aprovados pelo CEUA do campus da USP de Ribeirão Preto (Protocolo no 142/2017). Resultados: A atividade nitrato redutase das bactérias da cavidade oral foi diminuída pelo uso de enxaguante. A pressão sistólica aumentou significativamente nos ratos $2 \mathrm{R} 1 \mathrm{C}$ em relação aos do grupo Sham já na primeira semana de hipertensão. O tratamento com L-arginina foi capaz de diminuir a pressão arterial em todas as semanas e o enxaguante reverteu significativamente $o$ efeito da L-arginina nas semanas 3,5 e 6 . Em relação à reatividade de aorta, a hipertensão foi capaz de diminuir o relaxamento à acetilcolina, ocasionando prejuízos tanto no pD2 quanto no Emax. A L-arginina foi capaz de melhorar a função vascular dos ratos hipertensos, tornando a resposta de relaxamento à acetilcolina semelhante à dos grupos Sham e a administração concomitante com enxaguante reverteu essa melhora. Nos ratos hipertensos, o tratamento com L-arginina aumentou as concentrações de nitrato na aorta e o enxaguante reverteu esse aumento. Ainda, o enxaguante bucal tendeu a diminuir as concentrações plasmáticas de nitrito, espécies nitrosiladas e nitrosotiois. Conclusão: Em nosso estudo, a L-arginina foi capaz de ocasionar diminuição nos valores pressóricos e melhora na função vascular, sendo estes efeitos diminuídos pelo enxaguante oral. Portanto, sugere-se que a integridade funcional do ciclo ênterosalivar do nitrato é importante para o efeito anti-hipertensivo da L-arginina.

Palavras-chave: L-arginina, Enxaguante bucal, ciclo êntero-salivar do nitrato, efeitos vasculares, efeitos anti-hipertensivos. 


\begin{abstract}
BATISTA, R.I.M. Mouthwash inhibits the antihypertensive effects of L-arginine in 2R1C hypertension model.2019. 65f. Dissertação (Mestrado) - Faculdade de Medicina de Ribeirão Preto, Universidade de São Paulo, Ribeirão Preto, 2019.

Introduction: Nitric oxide (NO) is produced by nitric oxide synthases (NOS), having as the only substrate for this production the amino acid L-arginine. In addition to this pathway, the bioavailability of $\mathrm{NO}$ can be increased by the enterosalivary cycle of nitrate in which the presence of oral bacteria with nitrate reductase activity is limiting. Thus, the hypothesis of this waork is that mouthwash would attenuate the beneficial effects of L-arginine in hypertension. Methods: Hannover rats were divided into 4 groups SHAM and 4 groups 2 kidney 1 Clip (2k1C) with the treatments vehicle (water), Mouthwash, L-arginine and L-arginine+Mouthwash. The treatment with Larginine was made in the drinking water in a concetration of $10 \mathrm{~g} / \mathrm{L}$ and the mouthwash was applied in the oral mucosa with the aid of a swab. The systolic pressure was monitored weekly and at the end of the 4 weeks of treatment, all animals were submitted to analysis of nitrate reductase activity of oral bacteria, as well as aortic reactivity and plasma and aorta collection for biochemical analyzes. All procedures were approved by the CEUA of the USP campus of Ribeirão Preto (Protocol no 142/2017). Results: The nitrate reductase activity of oral bacteria was decreased by the use of mouthwash. Systolic blood pressure increased significantly in the $2 \mathrm{~K} 1 \mathrm{C}$ rats compared to the Sham group in the first week of hypertension. Treatment with L-arginine was able to lower blood pressure in all treatment weeks and the mouthwash significantly reversed the effect of L-arginine at weeks 3,5 and 6 . Regarding aortic reactivity, hypertension was able to decrease relaxation to acetylcholine, causing damage in both pD2 and in Emax. L-arginine was able to improve the vascular function of hypertensive rats, making the acetylcholine relaxation response similar to that of Sham groups and concomitant administration with mothwash reversed this improvement. In hypertensive rats, treatment with L-arginine increased nitrate concentrations in the aorta and the mouthwash reversed this increase. Also, mouthwash tended to decrease plasma concentrations of nitrite, nitrosylated species and nitrosotiois. Conclusion: In our study, L-arginine was able to reduce blood pressure and to improve vascular function in hypertensive rats and the mouthwash was able to reverse these effects. Therefore, it is suggested that maintenance of the enterosalivary cycle is important for the antihypertensive effect of L-arginine.
\end{abstract}

Key words: L-arginine, mouthwash, nitrate-salivary cycle, vascular effects, antihypertensive effects. 


\section{LISTA DE FIGURAS}

Figura 1. Mecanismos envolvidos na diminuição da biodisponibilidade de NO e

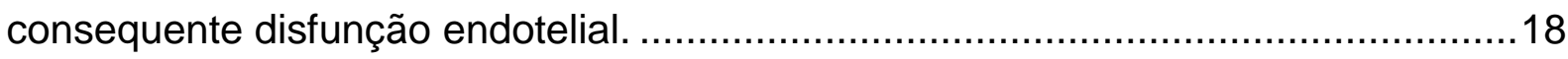

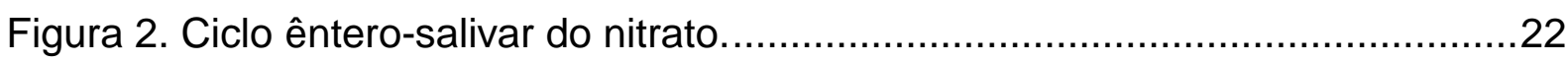

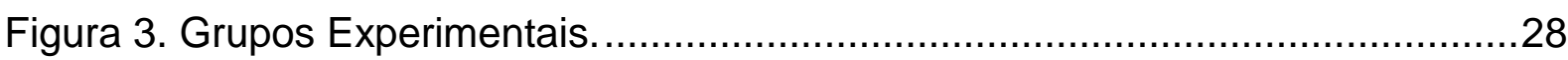

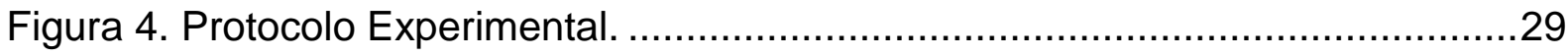

Figura 5. O enxaguante bucal foi capaz de reduzir a quantidade de unidades formadoras de colônias (UFC) da cavidade oral.

Figura 6. $O$ enxaguante bucal foi capaz de reduzir a atividade nitrato redutase da cavidade oral. .36

Figura 7. O enxaguante bucal foi capaz de reverter os efeitos anti-hipertensivos da Larginina.

Figura 8. O enxaguante bucal foi capaz de reverter a melhora na função vascular exercida pela L-arginina. 40

Figura 9. O enxaguante bucal foi capaz de reverter o aumento da resposta máxima e da potência $(\mathrm{pD} 2)$ de relaxamento à acetilcolina ocasionados pela L-arginina.

Figura 10. O enxaguante bucal tendeu a diminuir as concentrações plasmáticas de nitrito. .43

Figura 11. O enxaguante bucal tendeu a diminuir as concentrações plasmáticas de espécies nitrosiladas e nitrosotiois.

Figura 12: O enxaguante bucal foi capaz de reverter o aumento na concentração de nitrato na aorta ocasionado pela L-arginina nos ratos $2 \mathrm{R} 1 \mathrm{C}$. .46 


\section{LISTA DE ABREVEATURAS E SIGLAS}

2R1C- 2 rins 1 clipe

ACh- Acetilcolina

ADMA- Dimetilarginina assimétrica

ANOVA- Análise de variância

ATP- Adenosina-5'-trifosfato

$\mathrm{BH}_{4}$ - Tetraidrobiopterina

BHI- Brain Heart Infusion

CHX- Clorexidina

CMLVs- Células musculares lisas vasculares

DCV- Doenças cardiovasculares

EDHF- Fator hiperpolarizante dependente do endotélio

Emax- Efeito máximo

eNOS- Óxido nítrico sintase endotelial

FAD- Dinucleótido de flavina e adenina

FMN- Mononucleótido de flavina

GC-Guanilil ciclase

GMPc- Monofosfato de guanosina 3'5' cíclico

GSNO- S-nitrosoglutationa

GTP- Guanosina trifosfato

HAS- Hipertensão arterial sistêmica

$\mathrm{HNO}_{2}$ - Ácido nitroso

iNOS- Óxido nítrico sintase induzível

IRAG- Inositol 1,4,5-trifosfato

Kca- Canais de potássio dependentes de cálcio 
MLCP- Fosfatase da cadeia leve de miosina

$\mathrm{N}_{2} \mathrm{O}_{3}$ - Anidrido nitroso

NADPH- Nicotinamida adenina dinucleótido fosfato reduzida

nNOS- Óxido nítrico sintase neuronial

NO- Óxido Nítrico

NO+- Íons nitrosônio

$\mathrm{NO}_{2}$ - Nitrito

$\mathrm{NO}_{3}=$ Nitrato

NOS- Óxido nítrico sintases

O2- Oxigênio molecular

ONOO- Peroxinitrito

pD2- Logaritmo negativo da concentração que produz metade do efeito máximo

PDEs- Fosfodiesterases

PKG- proteína quinase G

ROS- Espécies reativas de oxigênio

RS- Ânion tiolato reduzido

RSNO- Nitrosotióis

RXNO- Espécies nitro(sil)adas

SERCA- Retículo sarcoplasmático ATPase

UFC- Unidades formadoras de colônias 


\section{SUMÁRIO}

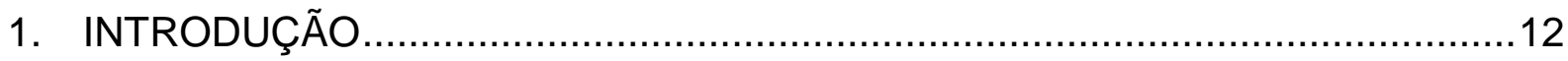

1.1. Hipertensão: Epidemiologia e fatores de risco …..................................12

1.2. Via canônica da produção do Óxido Nítrico e suas funções na homeostase vascular

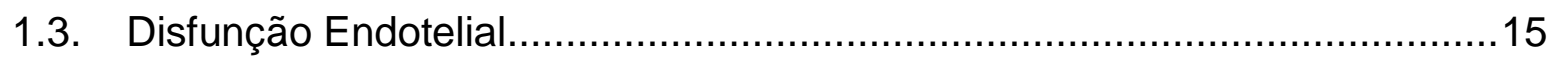

1.4. Efeitos da L-arginina na Hipertensão ...................................................18

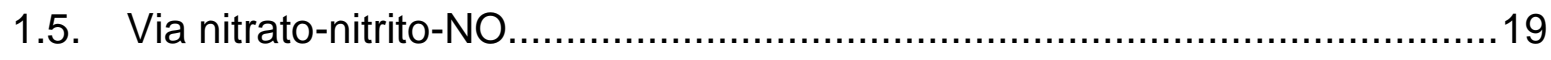

1.6. Participação da microbiota oral no efeito vasodilatador do NO ....................22

1.7. Efeitos do enxaguante bucal na conversão de nitrato a nitrito e formação de NO 23

2. HIPÓTESE .25

3. OBJETIVOS .26

3.1. Geral .26

3.2. Específicos .26

4. MATERIAIS E MÉTODOS .27

4.1. Animais .27

4.2. Hipertensão Arterial Induzida pela Técnica de Goldblatt. .27

4.3. Protocolo experimental. .27

4.3.1. Avaliação dos efeitos anti-hipertensivo e vasoprotetor da administração oral de L-arginina com ou sem utilização concomitante de enxaguante bucal. ..28 4.3.2. Contagem de Bactérias por Unidade Formadora de Colônias (CFU) ....29 
4.3.3. Avaliação da Atividade Nitrato Redutase:

4.3.4. Avaliação da pressão arterial:...................................................... 30

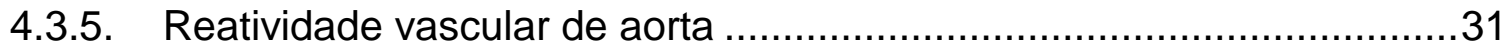

4.3.6. Determinação das concentrações plasmáticas de nitrato, nitrito e espécies nitros(il)adas

4.3.7. Determinação das concentrações teciduais (aorta) de nitrato e nitrito ..32

4.4. Análise dos resultados .33

5. RESULTADOS 34

5.1. Contagem de bactérias por Unidades formadoras de Colônias (UFC) ........34

5.2. Avaliação da Atividade Nitrato Redutase da cavidade oral .35

5.3. Avaliação da Pressão Arterial Sistólica

5.4. Avaliação da função vascular por reatividade vascular de aorta. 39

5.5. Concentrações plasmáticas de nitrato, nitrito, espécies nitros(il)adas e nitrosotiois .42

5.6. Concentrações teciduais (aorta) de nitrato e nitrito ..................................45

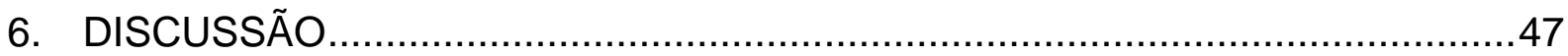

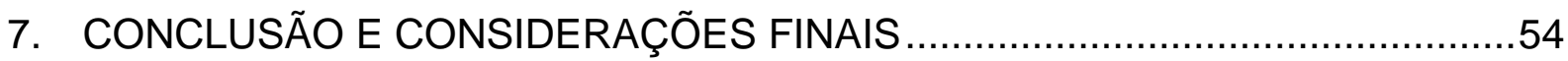

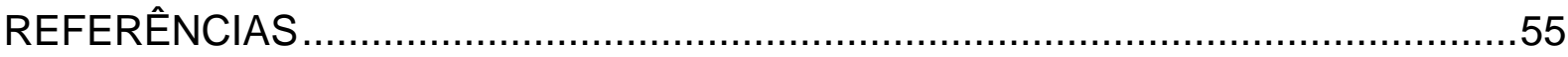




\section{INTRODUÇÃO}

1.1. Hipertensão: Epidemiologia e fatores de risco

As doenças cardiovasculares (DCV) correspondem a 17 milhões de mortes por ano, quase um terço do total de mortes no mundo (WHO, 2013). No Brasil, em 2013, ocorreram 1.138.670 óbitos, 339.672 dos quais decorrentes de DCV, a principal causa de morte no país (MALACHIAS et al., 2016). A hipertensão arterial sistêmica (HAS) é uma situação patológica multifatorial, sendo um importante fator de risco para o desenvolvimento de DCV, contribuindo direta ou indiretamente com $50 \%$ das mortes ocasionadas por estas (ATIK et al., 2018). A elevação sustentada dos níveis pressóricos em valores maiores ou iguais $140 \mathrm{mmHg}$ para a pressão sistólica e/ou maiores ou iguais a $90 \mathrm{mmHg}$ para a pressão diastólica determinam a existência da HAS (WHELTON et al., 2018). Um estudo mostrou que a prevalência de HAS entre os adultos ( $\geq 18$ anos) residentes nas capitais brasileiras e Distrito Federal foi de $24,1 \%$, sendo maior no sexo feminino (26,3\%) (CARVALHO MALTA et al., 2017).

Existem diversos fatores de risco para o desenvolvimento de doenças cardiovasculares, como a HAS, dentre eles podemos destacar a idade; o sexo e a etnia; o excesso de peso e a obesidade; a ingestão de sal e o consumo de álcool; além de fatores socioeconômicos e genéticos (MALACHIAS et al., 2016). Estes fatores têm se tornado cada vez mais relevantes diante de estudos que mostram que existe uma forte associação entre o envelhecimento e o desenvolvimento de HAS (MALACHIAS et al., 2016); que as mulheres e pessoas de raça negra/cor preta tendem a apresentar uma maior prevalência de HAS (BRASIL. MINISTÉRIO DA SAÚDE, 2014); que o excesso de peso tem aumentado entre indivíduos de 35 a 64 anos (MALACHIAS et al., 2016); que adultos com menores níveis de escolaridade tem maiores chances de desenvolver hipertensão (BRASIL. MINISTÉRIO DA SAÚDE, 
2014); que o consumo crônico e elevado de álcool pode causar elevação da pressão arterial e que o consumo de sal, no Brasil, excede em mais de duas vezes o recomendado (BRIASOULIS; AGARWAL; MESSERLI, 2012; TAYLOR et al., 2009). Em relação aos fatores genéticos, ainda não pôde ser identificado nenhum padrão para o desenvolvimento de HAS, sendo que isto se deve, principalmente, à miscigenação das populações, em especial a brasileira (KIMURA et al., 2013).

1.2. Via canônica da produção do Óxido Nítrico e suas funções na homeostase vascular

O Óxido Nítrico (NO) é uma molécula gasosa e lipofílica que permaneceu por muitos anos com seu papel fisiológico desconhecido. No entanto, após a descoberta de sua grande importância como fator relaxante derivado do endotélio, o mesmo começou a ser tratado como uma peça chave para a regulação do tônus vascular e da pressão arterial (FURCHGOTT; ZAWADZKI, 1980; IGNARRO et al., 1987; PALMER; FERRIGE; MONCADA, 1987). Atualmente, sabe-se que além do seu papel na regulação vasomotora, o NO também participa da neurotransmissão, regula a adesão celular ao endotélio, a inibição da agregação plaquetária (COOKE, J P; DZAU, 1997), a proliferação das células musculares lisas vasculares (CMLVs), entre outros (COCKCROFT, 2005) .

A via clássica ou canônica para produção de NO, nos mamíferos, ocorre em células endoteliais e se dá por ação das enzimas dependentes de cálcio-calmodulina, as óxido nítrico sintases (NOS) (ALDERTON; COOPER; KNOWLES, 2001). A forma da NOS que leva à produção de NO é a forma dimérica, que consiste na junção de dois monômeros idênticos, sendo que ambos são divididos em dois domínios, o domínio redutase C-terminal e o domínio oxigenasse N-terminal (GHOSH, DIPAK K; 
SALERNO, 2003; LI, HUIYING; POULOS, 2005). O domínio C-terminal contém sítios de ligação para o co-substrato nicotinamida adenina dinucleótido fosfato reduzida (NADPH) e para os cofatores dinucleótido de flavina e adenina (FAD) e mononucleótido de flavina (FMN), enquanto que o domínio N-terminal se liga ao grupo heme, ao cofator tetraidrobiopterina $\left(\mathrm{BH}_{4}\right)$ e ao substrato, a L-arginina (ORTIZ DE MONTELLANO et al., 1998; STUEHR, D J, 1997).

A L-arginina é o único substrato para a produção de NO via NOS, sendo que esta produção ocorre através de complexas reações que envolvem os co-substratos e cofatores descritos anteriormente, além do oxigênio molecular $\left(\mathrm{O}_{2}\right)$ (CYLWIK; MOGIELNICKI; BUCZKO, 2005). As reações necessárias para a produção de NO via NOS se dão em duas etapas, que consistem na hidroxilação da L-arginina em $\mathrm{N}^{\omega_{-}}$ hidroxi-L-arginina seguida pela oxidação desta pela NOS em NO e L-citrulina (TOUSOULIS, DIMITRIS et al., 2012). As NOS possuem 3 isoformas, a endotelial (eNOS), a induzível (iNOS) e a neuronial (nNOS), sendo a isoforma endotelial a que desempenha papel mais importante no sistema cardiovascular (ANDREW; MAYER, 1999; HUANG et al., 1995).

A atividade da eNOS é regulada pela formação do complexo CálcioCalmodulina nas células endoteliais, que é facilitada pelo aumento da $\left[\mathrm{Ca}^{2+}\right]$ na célula endotelial (OESS et al., 2006), sendo que este aumento pode se dar pela ação de agonistas, como a Acetilcolina (ACh), a histamina ou a bradicinina, além de estímulos físicos, como o estresse de cisalhamento (PALMER; ASHTON; MONCADA, 1988).

O NO formado a partir das NOS pode se difundir para as CMLVs, onde ativa a Guanilil ciclase (GC), o que possibilita a conversão de Guanosina trifosfato (GTP) em Monofosfato de guanosina 3'5' cíclico (GMPc) (FLEMING; BUSSE, 1999). Este último, 
se liga ao domínio regulatório da proteína quinase $\mathrm{G}$ (PKG), ocasionando uma alteração conformacional no sítio catalítico $\mathrm{N}$-terminal da proteína, que possibilita que a mesma tenha capacidade de fosforilar outras proteínas que atuam na homeostasia intracelular do $\mathrm{Ca}^{+2}$, incluindo a $\mathrm{Ca}^{+2}$-ATPase da membrana plasmática, o trocador $\mathrm{Na}^{+} / \mathrm{Ca}^{+2}$ e os canais de potássio dependentes de cálcio ( $\mathrm{K}_{\mathrm{Ca}}$ ), por exemplo (FRANCIS et al., 2010), levando a uma diminuição da concentração de $\mathrm{Ca}^{2+}$ intracelular e consequente vasodilatação (RAPOPORT; MURAD, 1983).

A PKG também pode gerar vasodilatação através da fosforilação da fosfolambam, o que faz com que a mesma se dissocie da retículo sarcoplasmático ATPase (SERCA), favorecendo o aumento da captação de $\mathrm{Ca}^{2+}$ pelo retículo sarcoplasmático (FRANCIS et al., 2010), além de também ser capaz de fosforilar o substrato associado ao receptor de inositol 1,4,5-trifosfato (IRAG), resultando na inibição da atividade do receptor de IP3 e na supressão da liberação de cálcio para o citoplasma (WALFORD; LOSCALZO, 2003). Adicionalmente, a PKG pode ativar a fosfatase da cadeia leve de miosina (MLCP), reduzindo a fosforilação da cadeia leve de miosina, também culminando na vasodilatação (SURKS et al., 1999). É importante ressaltar que os níveis de cGMP são regulados por um grupo de fosfodiesterases (PDEs) que controlam a hidrólise de cGMP, diminuindo sua biodisponibilidade (FRANCIS et al., 2010).

\subsection{Disfunção Endotelial}

A importância do endotélio vascular tem sido amplamente estudada desde sua descoberta por Furchgott e Zawadzki na década de 80 (FURCHGOTT; ZAWADZKI, 1980). Desde então, ele é conhecido como uma monocamada de células endoteliais que ajuda a compor a túnica íntima (camada mais interna) dos vasos sanguíneos, 
além de auxiliar na manutenção da saúde vascular e homeostase metabólica (ARTICLE; SHI; VANHOUTTE, 2017; GALLEY; WEBSTER, 2004; ZHANG et al., 2018). Além de ser responsável pela produção de NO, o endotélio também é capaz de secretar outras substâncias vasoativas, como as prostaciclinas, o fator hiperpolarizante derivado do endotélio (EDHF), o monóxido de carbono, a endotelina, prostanoides vasoativos e ânion superóxido (GHOSH, ARIJIT et al., 2017; LEE; YU, 2002). O desbalanço destas substâncias vasoativas com um aumento da produção de substâncias vasoconstritoras em detrimento das vasodilatadoras, em especial o NO, que tem sua produção e biodisponibilidade reduzidas, leva ao estabelecimento de um quadro conhecido como disfunção endotelial, sendo que esta está presente em diversas doenças como o diabetes, a hipertensão, a aterosclerose, entre outras (GALLEY; WEBSTER, 2004; RAVAROTTO et al., 2018).

A diminuição da biodisponibilidade de NO na disfunção endotelial pode se dar por um aumento do dimetilarginina assimétrica (ADMA) e consequente diminuição da atividade da eNOS, já que este é o inibidor endógeno da enzima, competindo com a L-arginina pela mesma (LIU et al., 2018). Já foi relatado, inclusive, que existe um aumento na concentração plasmática de ADMA em indivíduos hipertensos (MACALLISTER et al., 1994; PERTICONE et al., 2005).

A biodisponibilidade de L-arginina, o único substrato para a produção de NO, também parece estar comprometida na disfunção endotelial (MOSS et al., 2004). Apesar do "paradoxo da L-arginina" postular que a concentração endógena de Larginina intracelular $(0.1-4 \mathrm{mmol} / \mathrm{L})$ é bem acima do $\mathrm{Km}$ (concentração do substrato para qual a velocidade da reação é a metade da velocidade máxima necessária) para síntese de NO (BODE-BOGER; SCALERA; IGNARRO, 2007), já foi demonstrado que o influxo de L-arginina para as células endoteliais está diminuído em pacientes 
hipertensos (MOSS et al., 2004; PERTICONE et al., 2005). Ou seja, em muitas células e condições patológicas, o transporte de L-arginina está comprometido (BOGLE et al., 1996; DEVES; BOYD, 1998; TORRENTS et al., 1998). A diminuição da biodisponibilidade de NO também pode ser resultado de um aumento na expressão de arginase, a enzima responsável pelo metabolismo da L-arginina em ornitina (JOHNSON et al., 2015).

A disfunção endotelial também pode estar associada a um aumento na produção de espécies reativas de oxigênio (ROS) (MUELLER et al., 2005), sendo que existem diversas enzimas capazes de produzir ROS na parede vascular como a NADPH oxidase, a xantina oxidase, além de enzimas da cadeia respiratória mitocondrial (SESSA et al., 2012). A NADPH oxidase pode dar origem ao $\mathrm{O}_{2}{ }^{-}$, e este reagir com o NO dando origem a espécies pró-oxidantes como o peroxinitrito (ONOO). $\mathrm{O}$ peroxinitrito pode levar à oxidação do cofator $\mathrm{BH}_{4}$, ocasionando uma mudança de conformação da forma dimérica para a forma monomérica da eNOS, o que leva a formação do ânion superóxido ao invés de NO (LUNDBERG, J O et al., 1994).

Todos esses eventos culminam na diminuição da biodisponibilidade de óxido nítrico e consequente disfunção endotelial (MONCADA; PALMER; HIGGS, 1991), sendo que os mesmos estão resumidos na figura 1. 


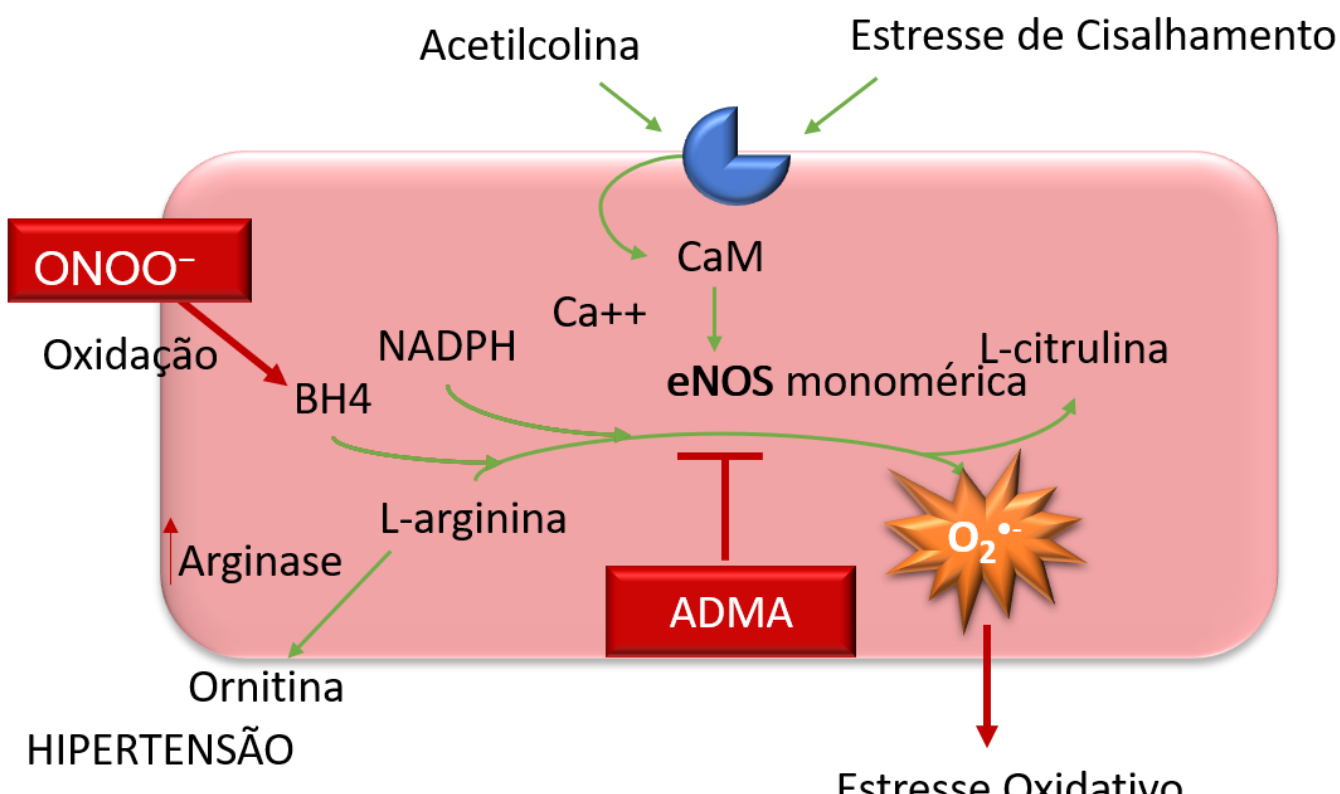

Figura 1. Mecanismos envolvidos na diminuição da biodisponibilidade de NO e consequente disfunção endotelial. Pode haver o aumento do ADMA (inibidor endógeno da eNOS), além da oxidação do cofator $\mathrm{BH} 4$ pelo peroxinitrito que pode levar a uma mudança de conformação da forma dimérica para a forma monomérica da eNOS, ocasionando a formação do ânion superóxido ao invés de NO. Também pode haver um aumento na metabolização da L-arginina por ação da enzima arginase, além de um aumento de ADMA, que causa uma diminuição na atividade da eNOS.

\subsection{Efeitos da L-arginina na Hipertensão}

Por ser o único substrato da produção de NO e por essa ser uma via de relaxamento utilizada por vários tecidos do corpo humano, a L-arginina é crucial na manutenção da homeostasia da resistência vascular periférica, da transmissão neuronal e da regulação da resposta imune (COOKE, JOHN P. et al., 1992). Pelo fato de a diminuição da disponibilidade de L-arginina e consequentemente de NO ser um fator determinante para a disfunção endotelial observada na hipertensão arterial, sugere-se que a suplementação com L-arginina gere uma potencialização da vasodilatação dependente do endotélio e consequente melhora da hipertensão (STUEHR, DENNIS J, 2004). Porém, os resultados de estudos nesse sentido ainda são controversos. 
Estudos em modelo de hipertensão 2 rins 1 clipe (2R1C) mostraram que a administração de L-arginina não alterou a pressão sistólica basal dos animais do grupo Sham, porém foi capaz de diminuir a pressão arterial dos animais hipertensos tratados em comparação com os não tratados, além de aumentar a excreção de sódio e água destes animais (GOUVÊA et al., 2003; GOUVEA et al., 2014). Em contrapartida, outros estudos não obtiveram diferença na pressão arterial de animais hipertensos tratados e não tratados com L-arginina, ou essa diferença só foi encontrada perante associação com outra droga, além de não terem sido encontrados aumentos nos metabólitos do óxido nítrico nestes mesmos grupos (DE LA RIVA et al., 2000; SANTUZZI et al., 2015).

Em estudos clínicos, a L-arginina vem sendo sugerida como uma forma de tratamento para o combate da disfunção endotelial na hipertensão (HIGASHI et al., 1995b). Em alguns estudos, a melhora na capacidade vasodilatadora foi capaz de gerar também uma diminuição da pressão arterial, porém em outros, essa diminuição não foi detectada (HIGASHI et al., 1995a; LEKAKIS et al., 2002). A L-arginina também foi capaz de diminuir os níveis séricos de endotelina 1 e angiotensina II, substâncias que desempenham um importante papel na hipertensão (PIATTI et al., 2003; STUEHR, DENNIS J, 2004).

\subsection{Via nitrato-nitrito-NO}

Os produtos finais do metabolismo endógeno do $\mathrm{NO}$, os ânions nitrato $\left(\mathrm{NO}_{3}{ }^{-}\right)$e nitrito $\left(\mathrm{NO}_{2}^{-}\right)$, já foram considerados inertes (LAUER et al., 2001), além de também já terem sido relacionados com a formação de $\mathrm{N}$-nitrosaminas e metahemoglobina, sendo a presença de ambas consideradas prejudiciais ao organismo (TANG; JIANG; BRYAN, 2011). No entanto, estudos realizados nas últimas décadas têm demonstrado 
que estes ânions podem ser reciclados fisiologicamente no sangue e nos tecidos para formar NO e outros óxidos de nitrogênio bioativos. Esta via de produção de NO pode ser complementar à via dependente das NOS (BJORNE; WEITZBERG; LUNDBERG, 2006; LUNDBERG, JON O; WEITZBERG, 2010; MONTENEGRO et al., 2011). Assim, existem duas possíveis fontes de nitrato e nitrito no organismo, a dieta e a via endógena L-arginina-NO sintase (COSBY et al., 2003; LUNDBERG, JON O; WEITZBERG, 2005; WEITZBERG; LUNDBERG, 1998). Considerando uma dieta oriental, os maiores fornecedores de nitrato oriundos da dieta são os vegetais, correspondendo a cerca de $60-80 \%$ da ingestão diária deste ânion (BRYAN; IVY, 2015). Além disso, o nitrato também pode ser ingerido durante o consumo de carnes, já que este é utilizado como aditivo alimentar para prevenir o botulismo e melhorar a aparência dos alimentos (HABERMEYER et al., 2015).

Vários estudos já demonstraram que estes ânions possuem efeitos fisiológicos e farmacológicos, especialmente em doenças cardiovasculares. Na hipertensão seus efeitos benéficos já foram demonstrados tanto em modelos animais (AMARAL et al., 2015; PINHEIRO et al., 2015) como em humanos (GHOSH, SUBORNO M et al., 2013) O NO formado a partir da L-arginina pode ser degradado através de oxidações comumente realizadas pelas oxi-hemoglobinas gerando primeiramente o metabólito intermediário nitrito que, posteriormente, é oxidado a nitrato (LUNDBERG, JON O.; WEITZBERG; GLADWIN, 2008). Este nitrato, após absorção no intestino e chegada na corrente sanguínea, é secretado ativamente pelas glândulas salivares para a boca, o que leva a saliva a ter concentrações 10-20 vezes maiores de nitrato que o plasma (FAASSEN et al., 2010). O nitrato oriundo da dieta juntamente com o que é derivado do NO endógeno são convertidos em nitrito por ação das bactérias da cavidade oral, podendo o nitrito ser transformado em NO no ambiente ácido do estômago ou ser 
absorvido no intestino e atuar fisiologicamente (LUNDBERG, JON O; WEITZBERG; GLADWIN, 2008). O NO pode ser novamente oxidado a nitrito e a nitrato, reiniciando o ciclo (LUNDBERG, JON O. et al., 2004).

O nitrito, ao chegar no estômago é convertido a ácido nitroso $\left(\mathrm{HNO}_{2}\right)$, que pode gerar NO livre (BENJAMIN et al., 1994). Além do NO, também são formadas espécies como o anidrido nitroso $\left(\mathrm{N}_{2} \mathrm{O}_{3}\right)$, que por ser uma potente fonte de nitrosilação, induz a formação de S-nitrosotióis, como a S-nitrosoglutationa (GSNO) (BRONIOWSKA; HOGG, 2012b). Na S-nitrosilação ocorre a incorporação do NO ao grupo tiol da cisteína (MARTÍNEZ-RUIZ; LAMAS, 2007) por meio do ataque ao ânion tiolato reduzido (RS-), formando o produto S-nitrosilado e nitrito (BRONIOWSKA; HOGG, 2012a; WINK et al., 1994).

Já foi demonstrado que a formação de S-nitrosotióis é crucial para a resposta anti-hipertensiva exercida pelo nitrito, indicando que a S-nitrosilação e transnitrosação de diferentes proteínas podem estar criticamente envolvidos nesta resposta (PINHEIRO et al., 2015). É importante ressaltar que o ambiente ácido do estômago é limitante para a formação das espécies derivadas do nitrito. Já foi observado, inclusive, que o aumento do $\mathrm{pH}$ gástrico alcançado pelo tratamento com omeprazol reduz os efeitos anti-hipertensivos ocasionados pelo nitrito oral em ratos (PINHEIRO et al., 2012). O ciclo êntero-salivar do nitrato está esquematizado na figura 2.

Apesar de os S-nitrosotióis serem comumente utilizados como doadores de NO, estudos recentes tem demonstrado que, de maneira semelhante à fosforilação, a S-nitrosilação pode alterar a função e a sinalização celular (OLIVEIRA-PAULA; TANUS-SANTOS, 2018). Já foi demonstrado, por exemplo, que a S-nitrosilação da cisteína 289 do receptor tipo 1 da angiotensina II reduz a sua afinidade de ligação à 
angiotensina II e que S-nitrosilação da NADPH oxidase inibe a produção de superóxido podendo preservar a biodisponibilidade do NO (LECLERC et al., 2006; SELEMIDIS et al., 2007).

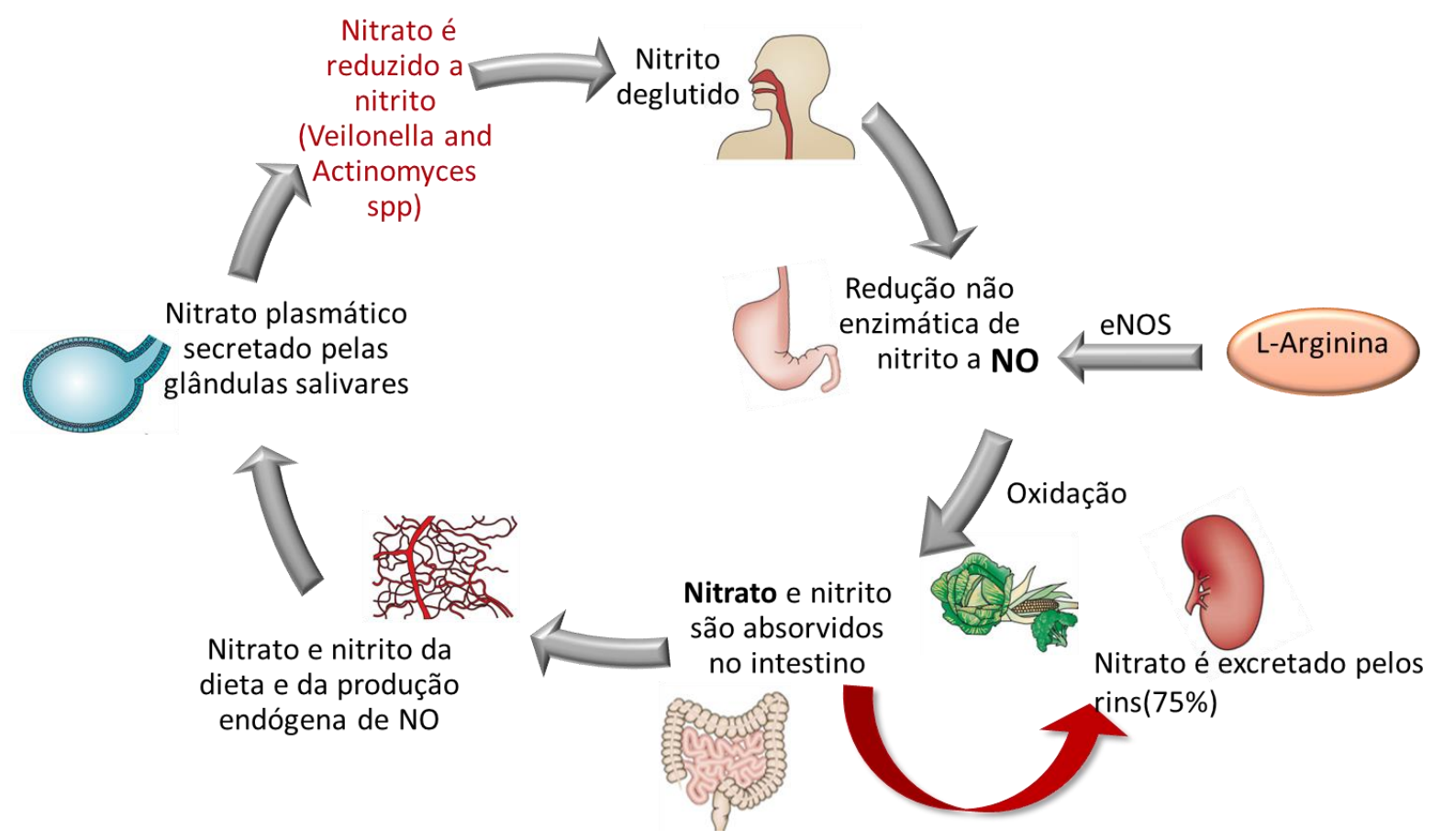

Figura 2. Ciclo êntero-salivar do nitrato. $O$ nitrato é reduzido a nitrito na cavidade oral por ação de bactérias anaróbico facultativas e este é reduzido a óxido nítrico e outras espécies nitrosantes no ambiente ácido do estômago. Essas espécies formadas nitrosilam proteínas e podem gerar vasodilatação. $O$ restante é oxidado a nitrato, sendo este absorvido e ativamente secretado pelas glândulas salivares, retornando à cavidade oral e reiniciando o ciclo. Adaptado de (LUNDBERG, JON O; WEITZBERG; GLADWIN, 2008).

\subsection{Participação da microbiota oral no efeito vasodilatador do NO}

Como dito anteriormente, para que o nitrato possa ser bioativado, este precisa ser reduzido a nitrito e esta reação é possibilitada exclusivamente por ação de bactérias anaeróbicas facultativas encontradas na parte dorsal da língua dos mamíferos (DUNCAN et al., 1995). Estas bactérias utilizam o nitrato como aceptor de elétrons para produzir adenosina-5'-trifosfato (ATP) durante a respiração, levando à redução deste nitrato a nitrito por ação das nitrato redutases (OLIVEIRA-PAULA; TANUS-SANTOS, 2018). É importante ressaltar que esta é uma reação incapaz de 
ser realizada por células de mamíferos, fazendo com que a redução de nitrato a nitrito na cavidade oral seja ausente em animais germ-free (WARD; COATES; WALKER, 1985). Nesse sentido, tem sido descrito o importante papel da microbiota oral no efeito vasodilatador do NO (JANSSON et al., 2008; KAPIL et al., 2013a).

Estudos realizados em indivíduos saudáveis isolaram e identificaram os principais e mais abundantes gêneros de bactérias responsáveis pela redução de nitrato a nitrito na cavidade oral. Dentre eles, estão os gêneros Veillonella, Actinomyces, Rothia, Staphylococcus, Propionibacterium, Prevotella, Neisseria, e Haemophilus, sendo o gênero Veillonella o mais abundante detectado nas raspagens da língua realizadas em um desses estudos (HYDE; ANDRADE; et al., 2014; JJ et al., 2005). Curiosamente, apenas a suplementação com nitrito de sódio já se mostrou capaz de alterar a composição da microbiota oral de ratos wistar, aumentando a quantidade de bactérias com capacidade nitrato redutase (HYDE; LUK; et al., 2014).

A identificação das bactérias responsáveis pela redução de nitrato a nitrito e das possíveis alterações nas quantidades das mesmas diante de uma situação patológica, poderiam ser utilizados até mesmo como biomarcadores de diminuição da biodisponibilidade de NO (HYDE; ANDRADE; et al., 2014). A diminuição destas bactérias diante do uso de enxaguantes bucais, por exemplo, tem sido relacionado com o aumento da pressão arterial em indivíduos saudáveis (GOVONI et al., 2008; KAPIL et al., 2013a). Recentemente, um estudo mostrou uma redução dos efeitos antihipertensivos do nitrato, mas não do nitrito perante a utilização de enxaguante bucal (PINHEIRO; FERREIRA; et al., 2016).

1.7. Efeitos do enxaguante bucal na conversão de nitrato a nitrito e formação de NO 
A microbiota oral é crucial para a manutenção dos efeitos vasodilatadores do NO já que esta é responsável por gerar o nitrito que será convertido em NO e espécies relacionadas no estômago (JANSSON et al., 2008; KAPIL et al., 2013a). Nesse sentido, quaisquer possíveis alterações na capacidade nitrato redutase das bactérias orais poderiam diminuir a conversão de nitrato a nitrito e sua consequente metabolização em NO (KAPIL et al., 2013b). Uma das maneiras de interferir nesse ciclo é fazendo uso de enxaguantes bucais, que conhecidamente, diminuem a quantidade de bactérias orais (PETERSSON et al., 2009).

Entre os enxaguantes bucais mais utilizados, a clorexidina ( $\mathrm{CHX})$ é conhecida como o agente químico mais potente, sendo eficaz na diminuição tanto de bactérias aeróbicas quanto anaeróbicas facultativas (bactérias responsáveis pela redução de nitrato a nitrito na cavidade oral) (HAERIAN-ARDAKANI et al., 2015). O mecanismo de ação da $\mathrm{CHX}$ inclui interações com componentes extracelulares e com a membrana citoplasmática, induzindo extravasamento de componentes intracelulares, além de interações com constituintes citoplasmáticos, causando morte celular bacteriana (SAFFARI et al., 2015). Já foi demonstrado que, em humanos, a utilização de $\mathrm{CHX}$ diminui a liberação de NO em quase 50\% 90 min após a ingestão de nitrato (ZETTERQUIST et al., 1999). Portanto, ao diminuir a quantidade de bactérias da cavidade oral diante da utilização de enxaguante bucal, também há a diminuição da conversão de nitrato a nitrito, diminuindo a produção de NO no estômago e na corrente sanguínea (GOVONI et al., 2008). 


\section{HIPÓTESE}

Como dito anteriormente, um aumento na biodisponibilidade de L-arginina pode ocasionar um aumento na formação de NO, sendo que este poderá ser convertido a nitrato, dependendo, este último, da integridade do ciclo êntero-salivar para produzir seus efeitos. Neste sentido, a hipótese deste trabalho é de que para exercer seus efeitos vasculares, a L-arginina seria dependente não só da sua conversão direta em óxido nítrico pela ação da eNOS, mas também do ciclo êntero-salivar do nitrato, que é dependente da conversão de nitrato a nitrito pelas bactérias presentes na mucosa oral. Portanto, a administração concomitante de L-arginina e enxaguante bucal, que causa uma diminuição desta flora bacteriana, atenuaria os efeitos benéficos da Larginina na função vascular e, consequentemente, seus efeitos em doenças cardiovasculares como a hipertensão. 


\section{OBJETIVOS}

\subsection{Geral}

- Verificar se a utilização de enxaguante bucal pode atenuar os efeitos benéficos exercidos pela L-arginina na hipertensão.

\subsection{Específicos}

- Comparar os efeitos vasculares e anti-hipertensivos da administração oral de Larginina com ou sem utilização concomitante de enxaguante bucal em ratos hipertensos 2R1C;

- Avaliar as concentrações de nitrato, nitrito, espécies nitrosiladas e nitrosotiois em amostras de plasma de ratos Sham e hipertensos 2R1C, tratados com L-arginina, enxaguante bucal ou veículo;

- Determinar os níveis totais de nitrato e nitrito em aortas de ratos Sham e hipertensos 2R1C, tratados com L-arginina, enxaguante bucal ou veículo. 


\section{MATERIAIS E MÉTODOS}

\subsection{Animais}

Foram utilizados ratos machos Hannover (180 a 200 gramas), provenientes do Biotério Central do Campus de Ribeirão Preto da Universidade de São Paulo. Os animais foram mantidos em salas com ciclos claro/escuro de 12 horas, temperatura controlada $\left(22-25^{\circ} \mathrm{C}\right)$ e acesso livre a ração e água.

\subsection{Hipertensão Arterial Induzida pela Técnica de Goldblatt}

Os animais foram mantidos no biotério de manutenção da Faculdade de Medicina de Ribeirão Preto durante uma semana para aclimatação e posteriormente foi feita a indução da Hipertensão Arterial. A técnica de Goldblatt, também conhecida como modelo 2 rins 1 clipe (2R1C), consiste na indução de estenose da artéria renal por meio de um clipe de prata com abertura de $0,2 \mathrm{~mm}$ e foi realizada conforme descrito anteriormente (GOUVÊA et al., 2003; LI, LI QIANG et al., 2017). Os animais foram anestesiados com uma combinação de cetamina e xilazina $(100 \mathrm{mg} / \mathrm{kg}$ e $5 \mathrm{mg} / \mathrm{kg}$, respectivamente) seguido por tricotomia e assepsia da área com álcool 70\% e iodopolividona para posterior laparotomia e colocação do clipe de prata ao redor da artéria renal esquerda. Os animais usados como controles foram submetidos apenas a laparotomia, sem introdução do clipe na artéria renal. Imediatamente após o procedimento cirúrgico, foi administrado banamine (flunixina meglumina, $2,5 \mathrm{mg} / \mathrm{kg}$ por via subcutânea) e baytril (enrofloxacina $10 \mathrm{mg} / \mathrm{kg}$ por via subcutânea). Os animais foram observados por até 24 horas após o processo cirúrgico. Os tratamentos foram iniciados após as duas semanas iniciais que se seguem à indução de hipertensão arterial renovascular.

\subsection{Protocolo experimental}


4.3.1. Avaliação dos efeitos anti-hipertensivo e vasoprotetor da administração oral de L-arginina com ou sem utilização concomitante de enxaguante bucal.

Nesse protocolo, uma parte dos ratos hipertensos (2R1C) e não hipertensos (SHAM) foram tratados com veículo (água), L-arginina (na água de beber $10 \mathrm{mg} / \mathrm{mL}$ ) e/ou enxaguante bucal (aplicado na mucosa oral com o auxílio de um swab) diariamente durante quatro semanas (início no começo da segunda após indução de HAS até o fim da sexta semana), resultando nos grupos: 2R1C+Veículo, 2R1C+Enxaguante bucal, 2R1C+L-arginina, 2R1C+Enxaguante bucal+Larginina, SHAM+Veículo, SHAM+Enxaguante bucal, SHAM+ L-arginina e SHAM+Enxaguante bucal+L-arginina. A figura 3 sumariza os grupos experimentais.

\begin{tabular}{|l|l|}
\hline SHAM & 2R1C \\
\hline Veículo & Veículo \\
\hline Enxaguante bucal & Enxaguante bucal \\
\hline L-Arginina $(10 \mathrm{mg} / \mathrm{mL})$ & L-Arginina $(10 \mathrm{mg} / \mathrm{mL})$ \\
\hline $\begin{array}{l}\text { L-Arginina }(10 \mathrm{mg} / \mathrm{mL})+\text { Enxaguante } \\
\text { bucal }\end{array}$ & $\begin{array}{l}\text { L-Arginina }(10 \mathrm{mg} / \mathrm{mL})+\text { Enxaguante } \\
\text { bucal }\end{array}$ \\
\hline
\end{tabular}

Figura 3. Grupos Experimentais.

O enxaguante bucal (Gluconato de Clorhexidina 0,12\%) foi aliquotado diariamente para aplicação em toda a mucosa oral do rato com um auxílio de um swab que foi embebido no mesmo. Os ratos dos grupos SHAM+Veículo ou L-arginina bem como 2R1C+Veículo ou L-arginina foram submetidos ao mesmo processo, porém o swab foi embebido em água milli-Q. Ao final das 4 semanas de tratamento, foi feita uma laparotomia para obtenção de sangue da veia cava inferior e, posteriormente, foi feita a eutanásia do animal com abertura do diafragma para isolamento da artéria aorta torácica. Neste procedimento, foi utilizado o anestésico tribromoetanol em uma dose 
de $250 \mathrm{mg} / \mathrm{kg}$. Todos os animais foram submetidos a análise das reatividades de aorta e posteriormente coleta de amostras (sangue e tecidos) conforme descrito abaixo. A figura 4 sumariza o protocolo.

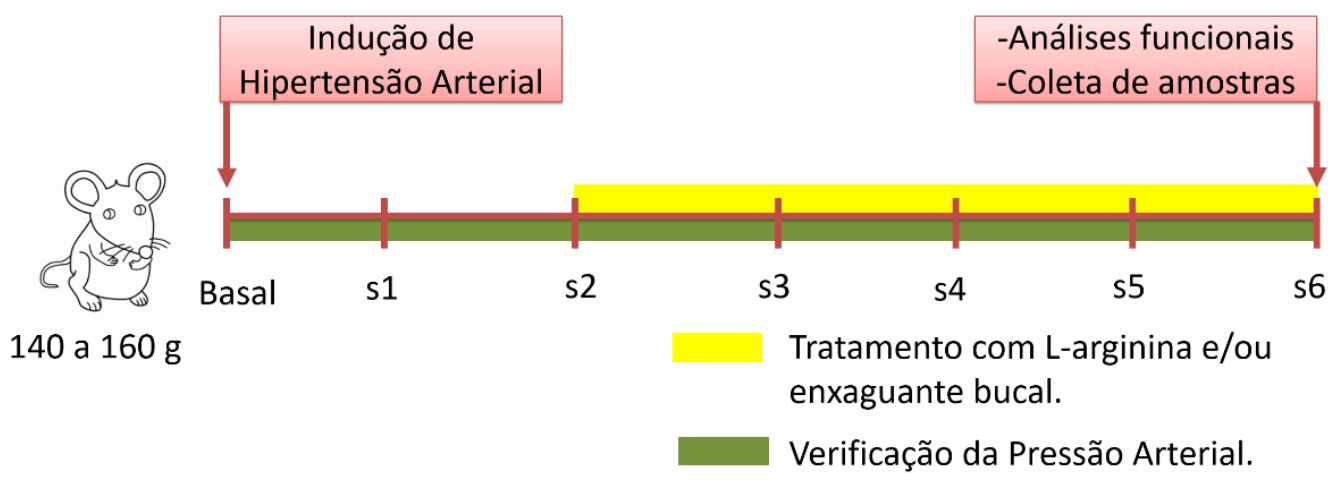

Figura 4. Protocolo Experimental.

A escolha da concentração de L-arginina na água de beber $(10 \mathrm{mg} / \mathrm{mL})$ se justifica pela sua utilização prévia em estudos, onde esta foi capaz de, em 14 dias, reduzir a pressão arterial de ratos com hipertensão renovascular (2R1C) (GOUVÊA et al., 2003; GOUVEA et al., 2014), enquanto que na utilização de doses menores não foi notada uma diminuição na pressão mesmo diante de um quadro de proteção contra mudanças no tônus vascular. Além disso, esta dose está dentro de um intervalo considerado seguro em ratos em um tratamento de até 91 dias (YANG et al., 2015).

\subsubsection{Contagem de Bactérias por Unidade Formadora de Colônias (CFU)}

Para avaliação da eficácia do enxaguante bucal no sentido de diminuir a quantidade de bactérias orais, foram utilizados ratos normotensos, dos quais foi coletado um swab da cavidade oral (contagem basal). Posteriormente, foi passado o enxaguante na cavidade oral desses ratos e foram coletados swabs duas horas após a utilização do enxaguante. As bactérias do swab (basal e duas horas após) foram 
cultivadas em uma placa contendo o meio sólido ágar nutriente e levadas à estufa a $3^{3} \stackrel{\circ}{ } \mathrm{C}$, onde foram encubadas por $18 \mathrm{hrs}$. Posteriormente, foram estimados o número de unidades formadoras de colônias (UFC) das placas individualmente (PINHEIRO; FERREIRA; et al., 2016).

\subsubsection{Avaliação da Atividade Nitrato Redutase:}

Para avaliação da eficácia do enxaguante bucal no sentido de diminuir a atividade nitrato redutase da cavidade oral por diminuição da quantidade de bactérias, foi realizada a avaliação da atividade nitrato redutase, baseada em técnica descrita anteriormente (AHMED et al., 2017). Para tanto, foi utilizado o meio líquido Brain Heart Infusion $(\mathrm{BHI})$ previamente autoclavado e testado quanto à esterilidade. Foram adicionados $1 \mathrm{~mL}$ do BHI em ependorffs estéreis para a inserção do swab embebido em salina e posteriormente passado na mucosa oral dos ratos. Após a coleta, foram quantificados os níveis basais de nitrito pelo método de quimiluminescência através de ozônio. Posteriormente, os ependorffs foram inseridos em um termomixer a uma temperatura de $37^{\circ} \mathrm{C}$ para incubação das bactérias orais por 1 hora. Após esse período, foram quantificadas novamente as concentrações de nitrito. Esperava-se que os valores de nitrito dos grupos não tratados com enxaguante aumentassem em relação ao basal pela presença de maior quantidade de bactérias nitrato retudase, se comparados com os animais tratados com enxaguante.

\subsubsection{Avaliação da pressão arterial:}

A fim de selecionar os animais em que a cirurgia gerou hipertensão e de monitorar a pressão dos animais SHAM, nas duas primeiras semanas, os animais tiveram a pressão arterial aferida em um aparelho de pletismografia de cauda usando um Pletismógrafo (CODA, KENT scientific). Os animais que apresentaram pressão 
sistólica inferior a $160 \mathrm{~mm} / \mathrm{Hg}$ ao final da segunda semana, foram excluídos do estudo. Durante as quatro semanas de tratamento, a pressão arterial continuou a ser monitorada por pletismografia de cauda para verificar os possíveis efeitos da Larginina nos animais SHAM e 2R1C e se estes efeitos poderiam ser interferidos pela utilização concomitante de enxaguante bucal.

\subsubsection{Reatividade vascular de aorta}

A fim de verificar se a hipertensão renovascular causaria prejuízos na função vascular dos ratos, se o tratamento com L-arginina poderia atenuar tais prejuízos e se a utilização do enxaguante bucal poderia reverter os efeitos da L-arginina foi realizada a reatividade vascular nas aortas dos ratos de todos os grupos de tratamento. Para isto, as artérias aortas foram coletadas, seccionadas em anéis de 3 a $4 \mathrm{~mm}$ e conectadas a um transdutor de deslocamento de força isométrica (Harvard Apparatus, Holliston, MA, USA) e mantida em câmera de banho para órgãos isolados contendo solução de Krebs com a seguinte composição $(\mathrm{mM})$ : $\mathrm{NaCl} 118, \mathrm{CaCl}_{2} .2 \mathrm{H}_{2} \mathrm{O}$ 2,5, $\mathrm{MgSO}_{4} .7 \mathrm{H}_{2} \mathrm{O}$ 1,64, $\mathrm{KH}_{2} \mathrm{PO}_{4} 1.2, \mathrm{KCl} 4.7, \mathrm{NaHCO}_{3} 24.9$, glicose 11,1 a $37^{\circ} \mathrm{C}, \mathrm{pH} 7,4$ ), borbulhado com mistura carbogênica $\left(95 \% \mathrm{O}_{2}\right.$ e $\left.5 \% \mathrm{CO}_{2}\right)$. Após isso, os anéis foram mantidos a uma pressão de $1,5 \mathrm{~g}$ por 1 hora para estabilização. Posteriormente, eles foram pré-contraídos com fenilefrina $\left(10^{-7} \mathrm{M}\right)$ e relaxados com acetilcolina $\left(10^{-6} \mathrm{M}\right)$ para a avaliação da integridade do endotélio, sendo que só foram inseridos anéis que apresentaram pelo menos $80 \%$ de relaxamento. Por fim, os anéis foram novamente contraídos com fenilefrina $\left(10^{-7} \mathrm{M}\right)$ e, posteriormente, relaxados com concentrações crescentes e cumulativas de Acetilcolina $\left(10^{-10} \mathrm{M}\right.$ a $\left.10^{-5} \mathrm{M}\right)$ para determinação da curva de relaxamento. Os resultados foram expressos como pD2 (logaritmo negativo da concentração que produz metade do efeito máximo) e Emax (efeito máximo) em 
resposta à Acetilcolina (OLIVEIRA-PAULA et al., 2016; PINHEIRO; OLIVEIRAPAULA; et al., 2016).

4.3.6. Determinação das concentrações plasmáticas de nitrato, nitrito e espécies nitros(il)adas

As amostras de plasma foram coletadas e colocadas em uma solução de NEM (10 mM) e DTPA (2 mM) (BRYAN et al., 2004b; FEELISCH et al., 2002) para análise pelo método de quimiluminescência através de ozônio. Resumidamente, para determinação do nitrito, $100 \mu \mathrm{l}$ de plasma foram injetados no aparelho contendo solução de iodo acidificada. O óxido nítrico formado então foi carreado pelo gás nitrogênio até o analisador de óxido nítrico (Sievers Modelo 280 NO analyzer, Boulder, CO). As concentrações plasmáticas de nitrato foram obtidas injetando $15 \mu \mathrm{l}$ de plasma no aparelho contendo vanádio (III) em ácido clorídrico a $90^{\circ} \mathrm{C}$, que reduz nitratos a NO gasoso (NAGASSAKI et al., 2006). O óxido nítrico formado então foi carreado, de maneira semelhante à descrita acima, pelo gás nitrogênio até o analisador de óxido nítrico. Para a quantificação de espécies nitro(sil)adas (RXNO), $500 \mu \mathrm{L}$ das amostras foram utilizadas. As amostras foram pré-encubadas com sulfanilamida ácida ( $5 \%$ em ácido clorídrico) na proporção de 10\% do volume da amostra. Após 5 minutos de reação, a amostra foi injetada no analisador como descrito acima. Para discriminar os nitrosotióis (RSNO), as medidas subtrativas foram realizadas usando amostras tratadas com $\mathrm{HgCl}_{2}(2 \%)$ antes da injeção em solução de iodeto acidificado. Os dados obtidos foram analisados pelo programa Origin 8.5 (OriginLab, Northampton, MA, EUA) (BRYAN et al., 2004a; FEELISCH et al., 2002).

4.3.7. Determinação das concentrações teciduais (aorta) de nitrato e nitrito

O tecido coletado foi macerado em macerador de vidro com PBS $\mathrm{pH} 7,4$ adicionado de NEM (10mM) e DTPA (2mM) para análise pelo método de 
quimiluminescência através de ozônio, conforme descrito anteriormente. Para os tecidos, resultados obtidos foram corrigidos pelo peso do tecido macerado.

\subsection{Análise dos resultados}

Os resultados funcionais e bioquímicos foram analisados por teste t (T-Student) ou análise de variância de dois fatores (two-way ANOVA) seguida por pós-teste de Tukey. Uma diferença estatística foi considerada significativa quando o valor de probabilidade foi menor que $0,05(\mathrm{P}<0,05)$. 


\section{RESULTADOS}

Inicialmente, foi possível observar se o tratamento com L-arginina seria capaz de ocasionar efeitos na pressão arterial e função vascular, além de verificar se o tratamento com enxaguante ocasionaria diminuição da contagem de bactérias da cavidade oral dos ratos e, consequentemente, interferiria em eventuais efeitos ocasionados pela L-arginina.

5.1. Contagem de bactérias por Unidades formadoras de Colônias (UFC)

Primeiramente, era necessário garantir que o enxaguante bucal estava ocasionando uma diminuição da quantidade de bactérias da cavidade oral e, como esperado, houve uma diminuição da quantidade de bactérias diante da utilização deste, teste $t_{(8)}=4,794,{ }^{*} p=0,0014$ em relação ao basal (Figura 5).

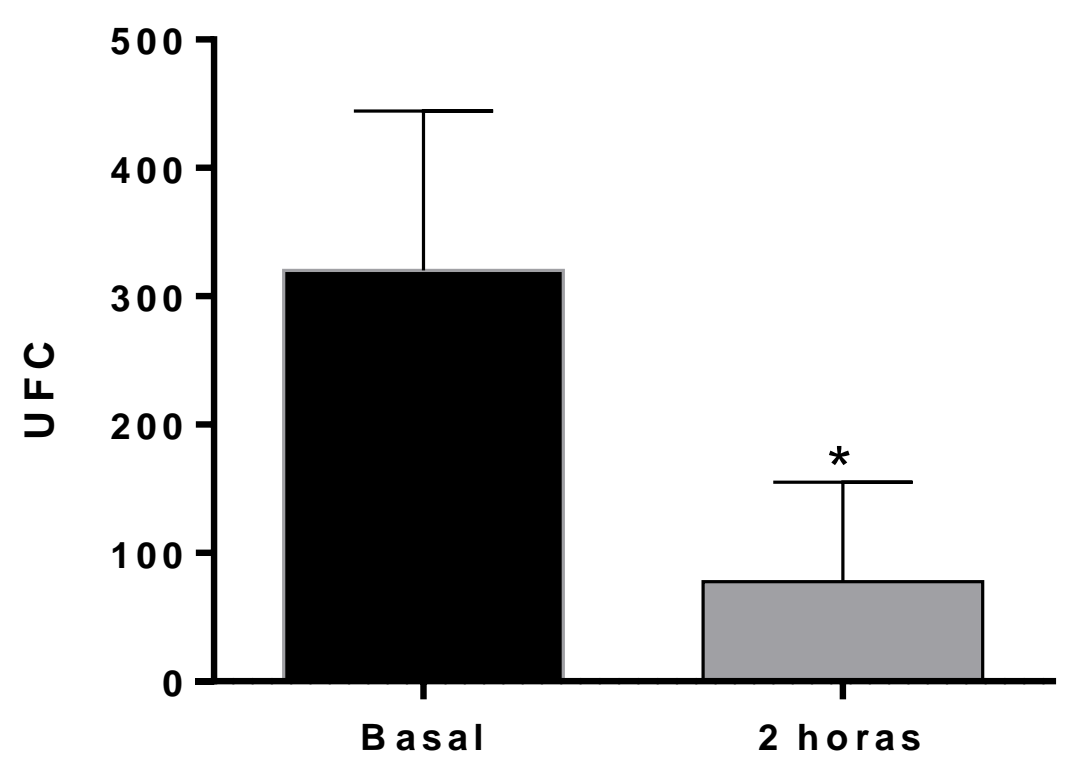

Figura 5. 0 enxaguante bucal foi capaz de reduzir a quantidade de unidades formadoras de colônias (UFC) da cavidade oral. Os swabs foram coletados antes e duas horas após a utilização do enxaguante bucal. Dados mostrados como média \pm S.E.M. ( $n=9$ por grupo) ${ }^{*} P<0,05$ versus grupo controle. 
5.2. Avaliação da Atividade Nitrato Redutase da cavidade oral

Posteriormente, foi verificado se a diminuição da quantidade de bactérias da cavidade oral ocasionaria também uma diminuição da atividade nitrato redutase desta região e consequente interrupção do ciclo êntero-salivar do nitrato. Como podemos observar, a capacidade nitrato redutase diminuiu diante da utilização de enxaguante bucal, teste $t_{(41)}=2.289,{ }^{\star} p=0,0273$ em relação ao veículo (Figura 6.A). No entanto, quando foi feita a divisão nos oito grupos do estudo, apesar de a tendência a essa diminuição ser mantida, esta deixou de ser estatisticamente significativa (Figura 6.B). 


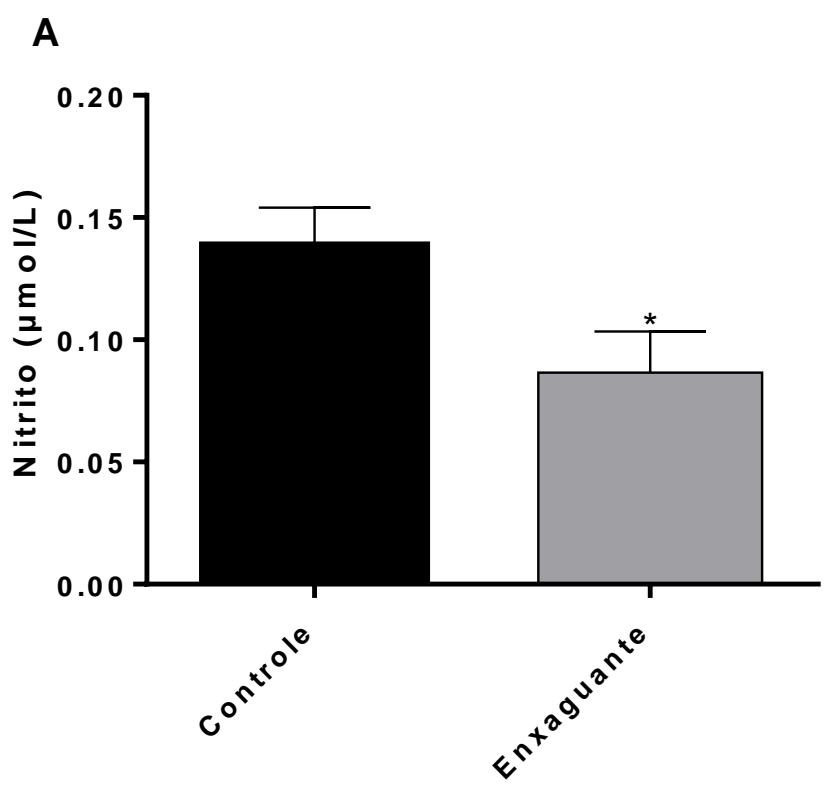

B

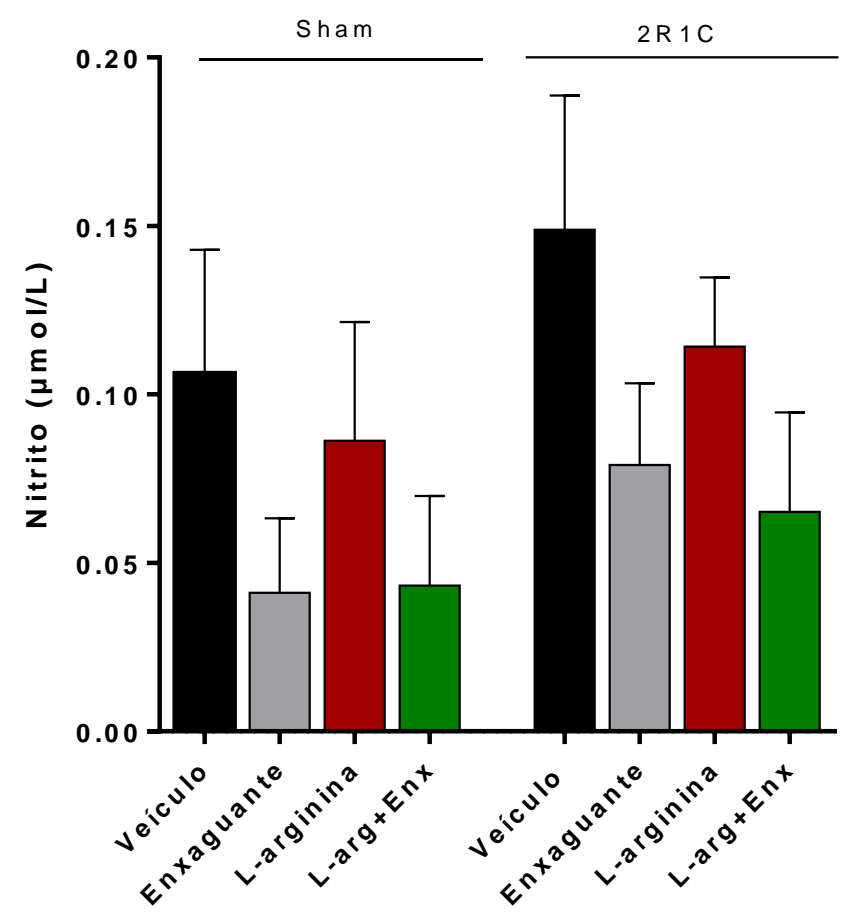

Figura 6. 0 enxaguante bucal foi capaz de reduzir a atividade nitrato redutase da cavidade oral. A Figura A mostra um panorama geral dos ratos que não receberam enxaguante (controle) e dos que receberam. ( $n=22$ por grupo). A figura B mostra os animais SHAM e 2R1C da figura A divididos em seus respectivos grupos de tratamento ( $n=3$ a 10 por grupo). Dados mostrados como média \pm S.E.M. ${ }^{*} \mathrm{P}<0,05$ versus grupo Controle. 


\subsection{Avaliação da Pressão Arterial Sistólica}

A pressão sistólica de cauda aumentou significativamente nos ratos $2 \mathrm{R} 1 \mathrm{C}$ em relação aos do grupo SHAM já na primeira semana de hipertensão ${ }^{*}{ }^{*} p<0,05$ em relação ao grupo SHAM+Veículo), demonstrando a eficácia do modelo utilizado. O tratamento com L-arginina (10 g/L), na água de beber, foi capaz de reduzir a pressão sistólica nas quatro semanas (\#p<0,05 em relação ao grupo $2 \mathrm{R} 1 \mathrm{C}+$ Veículo). $\mathrm{O}$ tratamento com enxaguante foi capaz de reverter a diminuição de pressão ocasionada pela L-arginina nas semanas 3, 5 e 6 (" $p<0,05$ em relação ao grupo 2R1C+L-arginina). O tratamento apenas com enxaguante não foi capaz de causar alterações na pressão tanto nos ratos SHAM quanto nos 2R1C. Nos animais normotensos, ambos os tratamentos (L-arginina e enxaguante bucal) não foram capazes de exercer efeitos na pressão sistólica dos animais. (Figura 7). 


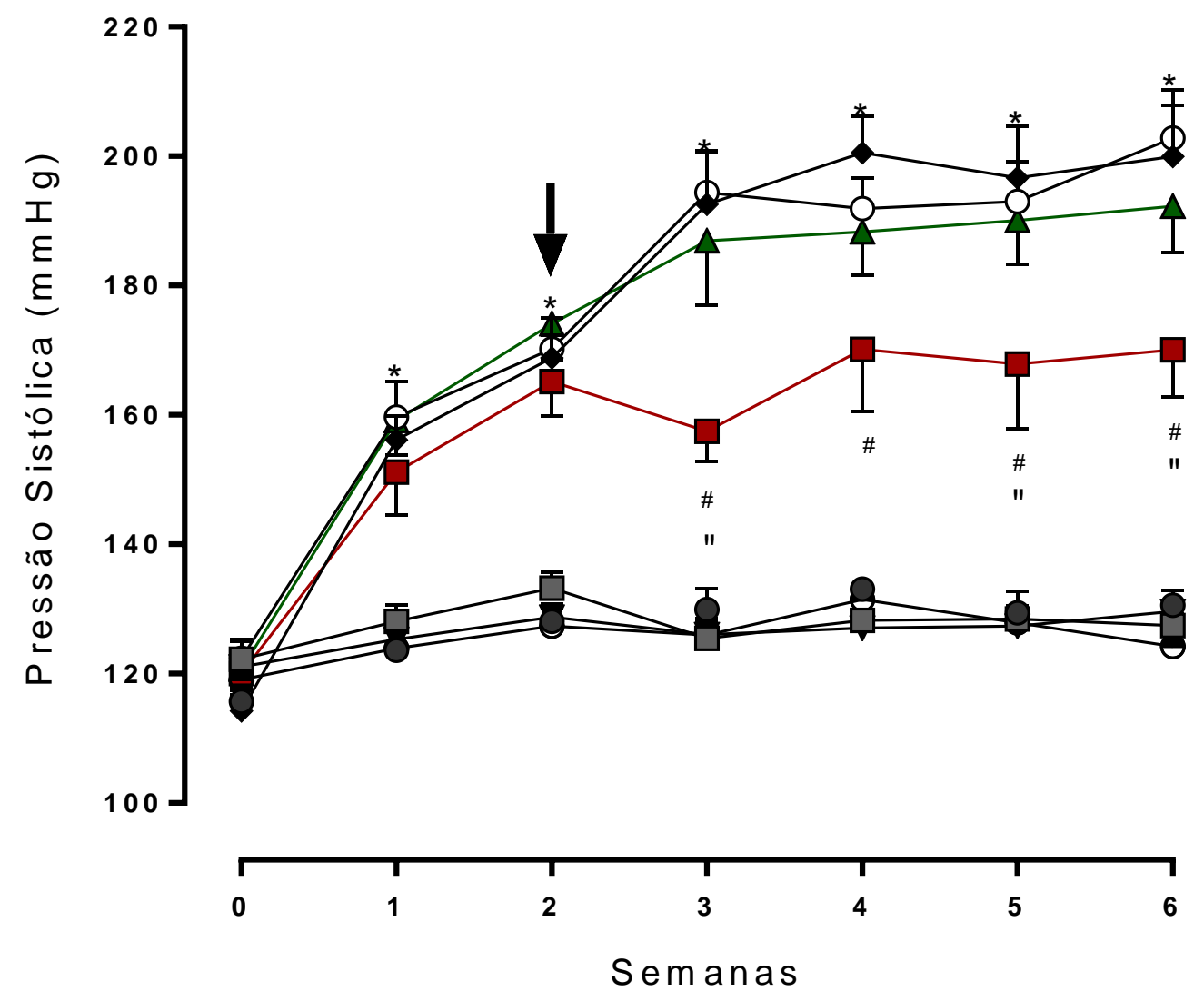

\footnotetext{
$\longrightarrow$ Sham + Veículo $(n=13)$

$\square \quad$ Sham +Enxaguante $(n=14)$

$\nabla$ Sham + L-Arginina $(n=15)$

- Sham +L-Arg+Enxaguante $(n=11)$
}

$\longrightarrow \quad 2 R 1 C+$ Veículo $(n=14)$

-O- $2 R 1 C+$ Enxaguante $(n=12)$

$\square \quad 2 R 1 C+L-A r g i n i n a(n=14)$

$\triangle \quad 2 \mathrm{R} 1 \mathrm{C}+\mathrm{L}-\mathrm{Arg}+\mathrm{Enxaguante} \mathrm{n}=12$ )

Figura 7. $O$ enxaguante bucal foi capaz de reverter os efeitos anti-hipertensivos da L-arginina. A Pressão arterial sistólica $(\mathrm{mmHg})$ foi aferida em um aparelho de pletismografia de cauda. Dados mostrados como média \pm S.E.M ( $n=11$ a 14 por grupo). ${ }^{*} \mathrm{P}<0,05$ versus grupo $S H A M+V e i ́ c u l o . ~ \# P<0,05$ versus grupo $2 \mathrm{R} 1 \mathrm{C}+\mathrm{Veículo.} \mathrm{"P}<0,05$ versus grupo $2 \mathrm{R} 1 \mathrm{C}$ ' $\mathrm{L}$-arg+Enxaguante. 
5.4. Avaliação da função vascular por reatividade vascular de aorta

No que diz respeito à função vascular da aorta dos ratos estudados, a hipertensão foi capaz de diminuir o relaxamento à acetilcolina, deslocando a curva para a direita (Figura 8), ocasionando prejuízos tanto no pD2 quanto no Emax $(\mathrm{pD} 2=7,92 \pm 0,05$ e Emax $=97,96 \pm 1,59$ para o SHAM+Veículo e pD2=7,39 $\pm 0,15$ e Emax $=74,76 \pm 3,88$ para o grupo $2 \mathrm{R} 1 \mathrm{C}+$ Veículo, com $\mathrm{p}<0,05$ entre os grupos). A Larginina foi capaz de melhorar a função vascular dos ratos hipertensos, tornando a resposta de relaxamento à acetilcolina semelhante à dos grupos Sham $(p D 2=7,52 \pm 0,15$ e Emax $=91,09 \pm 4,45$ para o grupo $2 R 1 C+L$-arginina, com $p<0,05$ em relação ao grupo 2R1C+Veículo), e a administração concomitante com enxaguante reverteu essa melhora $(\mathrm{pD} 2=0,079 \pm 0,087$ e Emax $=79,21 \pm 2,58$, com $p<0,05$ em relação ao grupo 2R1C+L-arginina) (Figuras 5.A e 5.B). Nesse sentido, foi observado um aumento no efeito máximo e na potência (pD2) de relaxamento à acetilcolina nos ratos hipertensos tratados com L-arginina e uma reversão desses aumentos diante do tratamento com enxaguante bucal ( ${ }^{*} p<0,05$ em relação ao grupo Sham+Veículo) (Figuras 9.A e 9.B). 


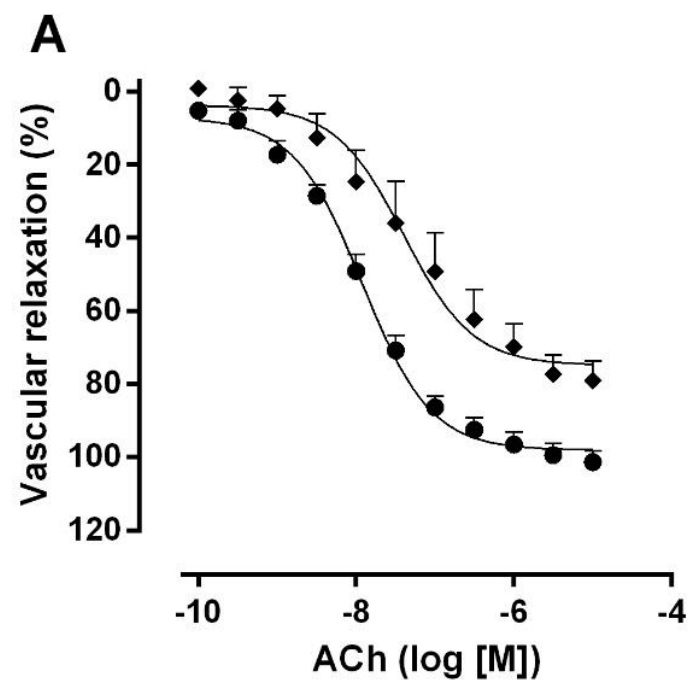

B
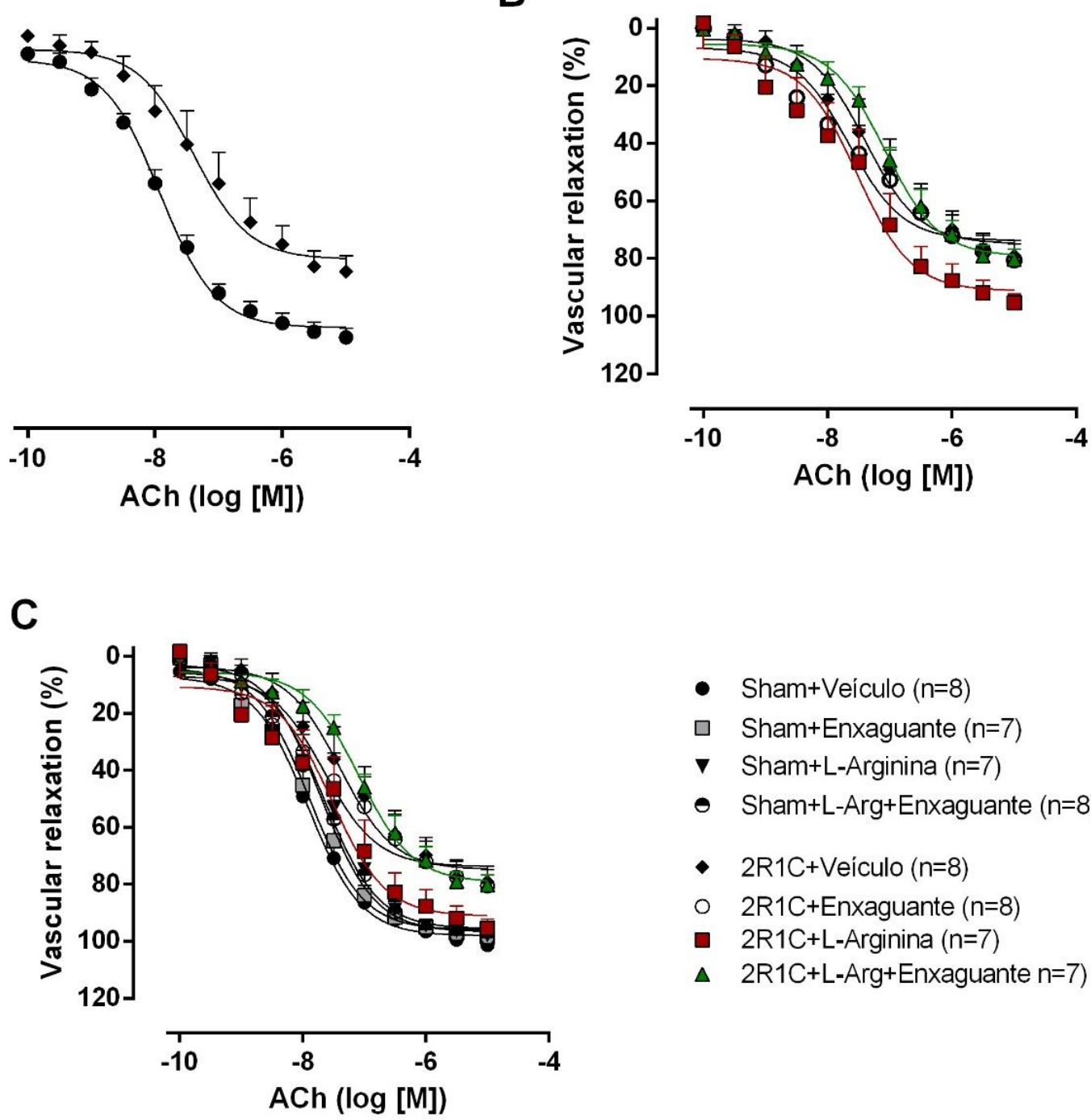

- Sham+Veículo $(\mathrm{n}=8)$

$\square \quad$ Sham+Enxaguante $(n=7)$

v Sham+L-Arginina $(n=7)$

- Sham+L-Arg+Enxaguante $(n=8)$

- 2R1C+Veículo $(n=8)$

- 2R1C+Enxaguante $(n=8)$

- 2R1C+L-Arginina $(n=7)$

$\Delta \quad 2 \mathrm{R} 1 \mathrm{C}+\mathrm{L}-\mathrm{Arg}+$ Enxaguante $\mathrm{n}=7$ )

Figura 8. 0 enxaguante bucal foi capaz de reverter a melhora na função vascular exercida pela L-arginina. A figura A mostra uma comparação entre os grupos Sham e $2 R 1 C$ tratados apenas com veículo. A figura $B$ mostra os ratos hipertensos tratados com $L$-arginina (ou veículo) e Enxaguante Bucal (ou veículo). A figura $\mathrm{C}$ mostra todos os grupos utilizados. ( $\mathrm{n}=7$ a 8 por grupo). 
A

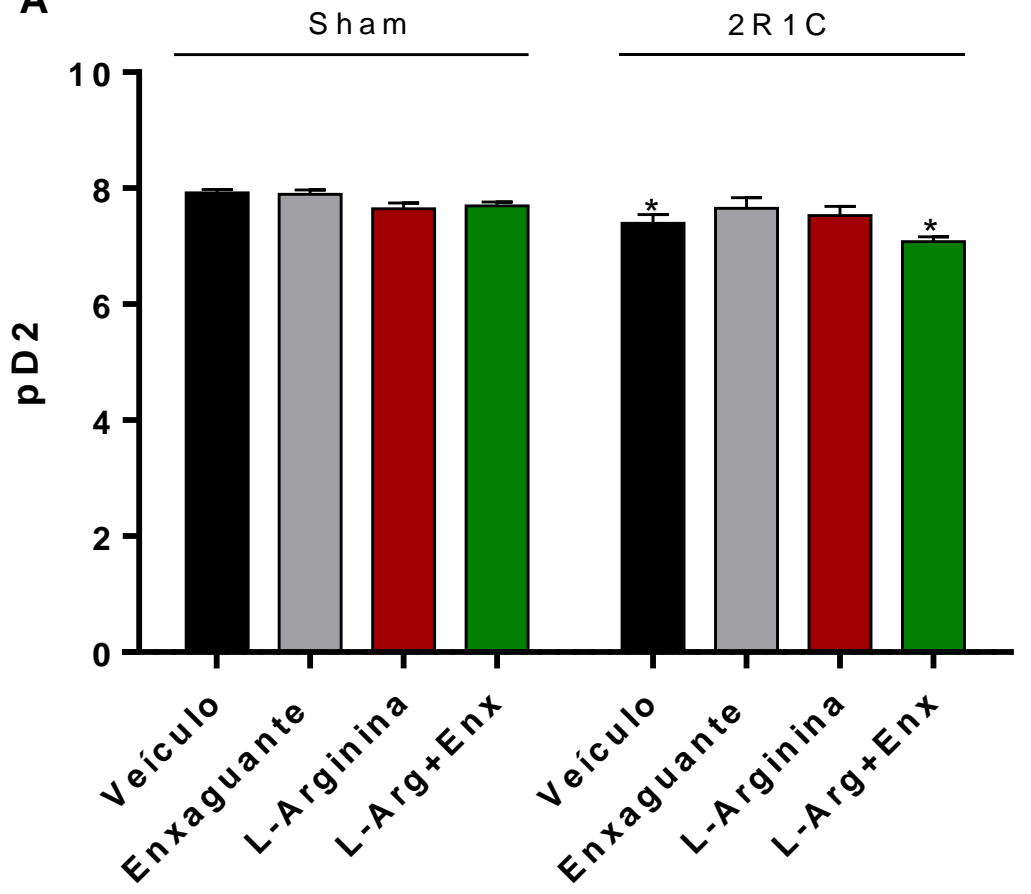

B

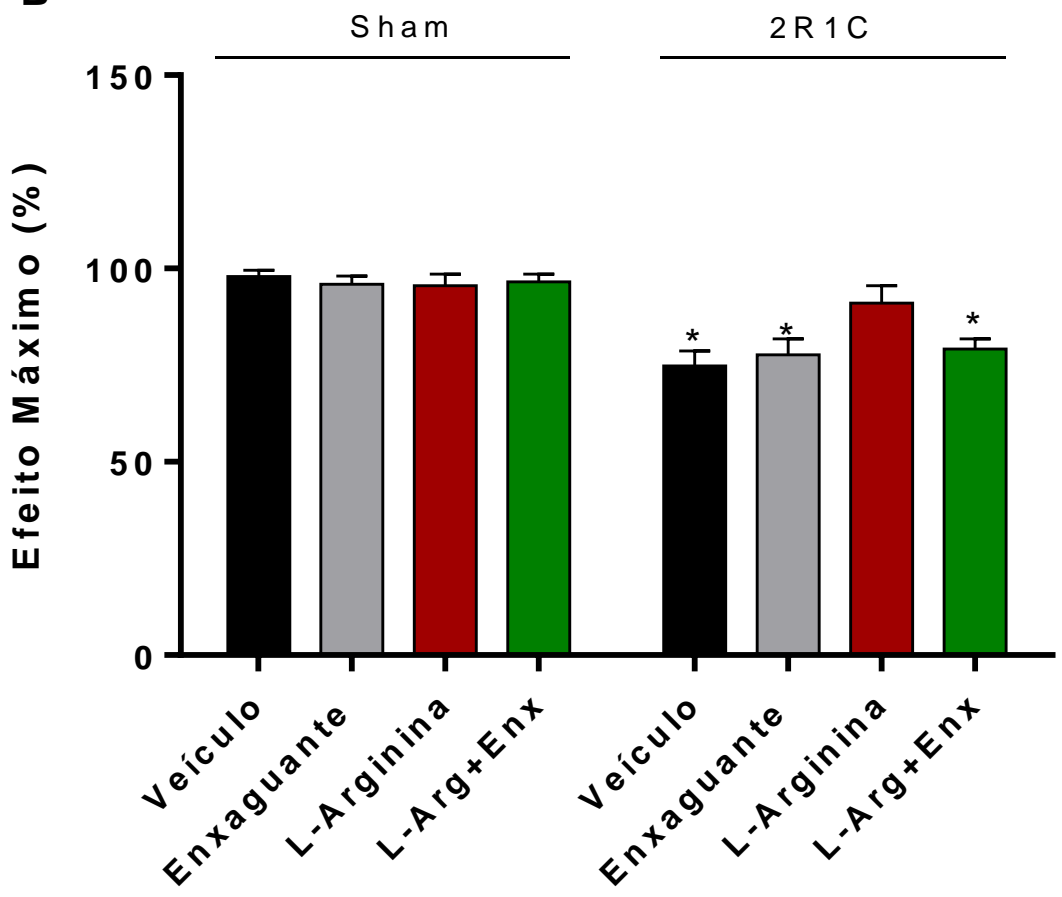

Figura 9. 0 enxaguante bucal foi capaz de reverter o aumento da resposta máxima e da potência (pD2) de relaxamento à acetilcolina ocasionados pela L-arginina. A figura $A$ mostra o efeito máximo de relaxamento à Acetilcolina dos grupos Sham e 2R1C. A figura B mostra o pD2 (logaritmo negativo da concentração que produz metade do efeito máximo) das curvas de relaxamento à Acetilcolina dos animais dos grupos Sham e 2R1C Dados mostrados como média \pm S.E.M ( $n=7$ a 8 por grupo). ${ }^{*} P<0,05$ versus grupo Sham+Veículo. 
Posteriormente, foi possível observar se os tratamentos com L-arginina e/ou enxaguante seriam capazes de ocasionar alterações nas concentrações dos metabólitos do óxido nítrico.

5.5. Concentrações plasmáticas de nitrato, nitrito, espécies nitros(il)adas e nitrosotiois

Em relação às concentrações plasmáticas de nitrito e nitrato, nos animais hipertensos, o uso de enxaguante tendeu a diminuir as concentrações de nitrito ( ${ }^{*} p<0,05$ em relação ao grupo Enxaguante com post hoc de Tukey) (Figura 10.B), enquanto as concentrações de nitrato não foram alteradas (Figura 10.A). O tratamento com enxaguante bucal, nos ratos $2 \mathrm{R} 1 \mathrm{C}$, também tendeu a diminuir tanto as concentrações de espécies nitros(il)adas (Figura 11.A), quanto as de nitrosotiois ( ${ }^{*} p<0,05$ em relação ao grupo veículo com post hoc de Tukey) (Figura 11.B), porém sem diferenças estatísticas para as espécies nitros(il)adas. 
A

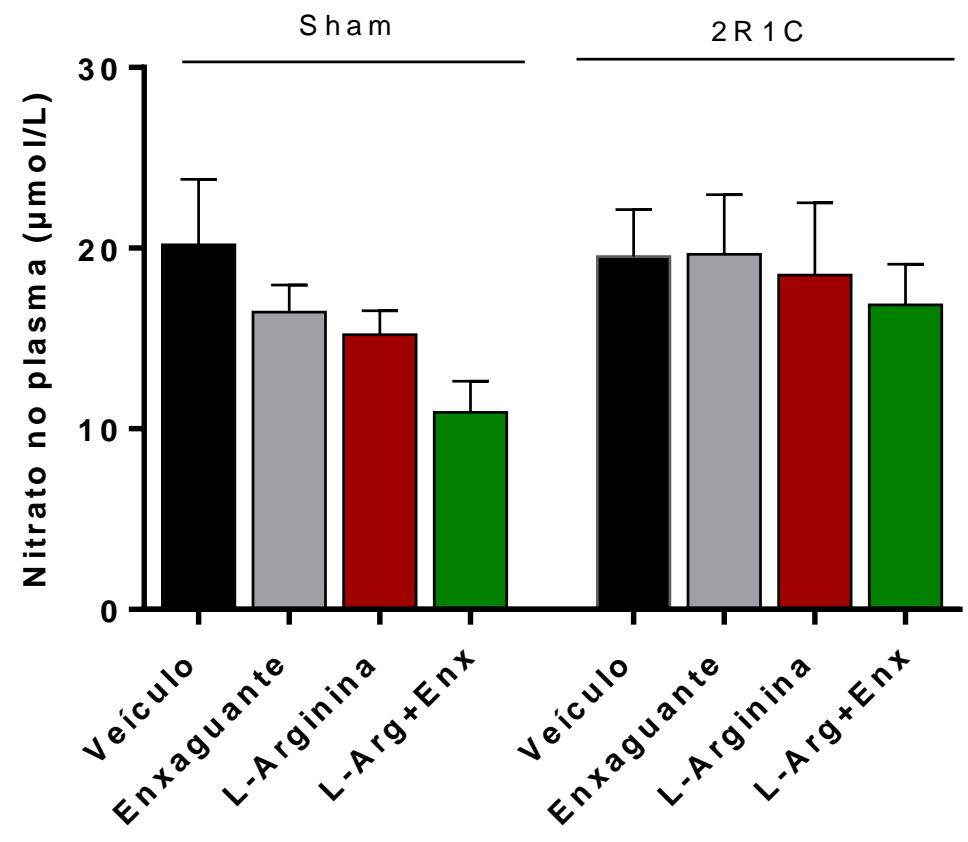

B

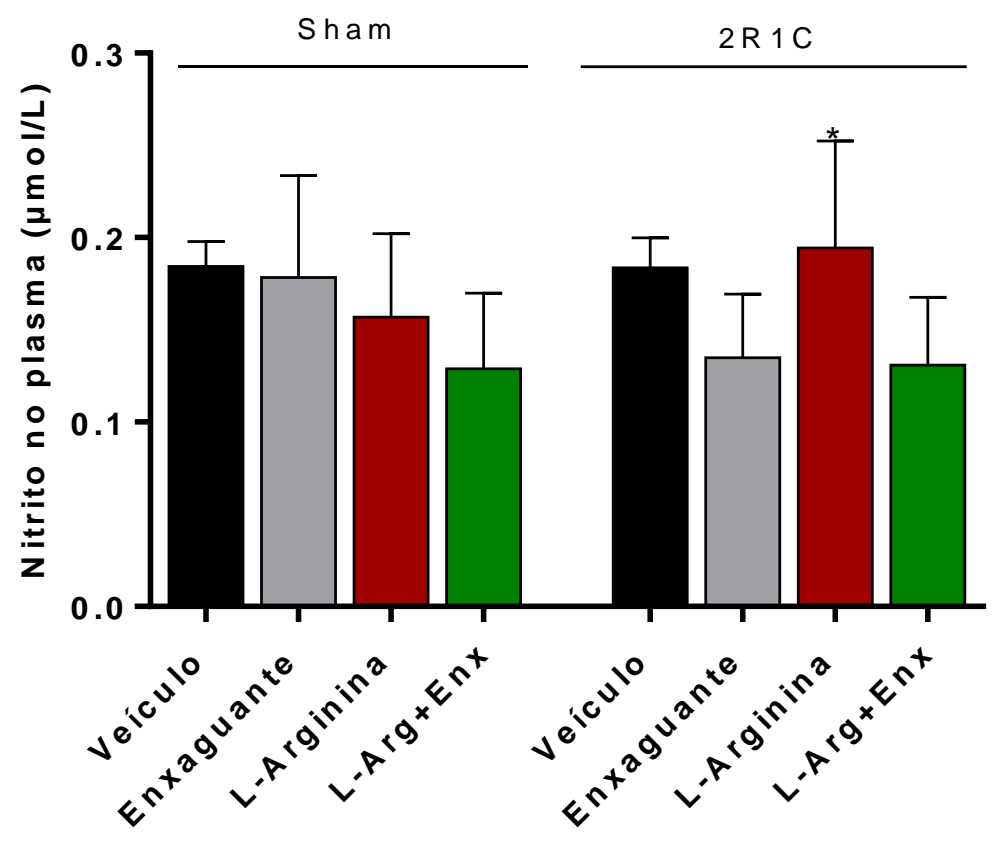

Figura 10. $O$ enxaguante bucal tendeu a diminuir as concentrações plasmáticas de nitrito. $A$ figura A mostra as concentrações plasmáticas de nitrato dos animais dos grupos Sham e 2R1C. A figura B mostra as concentrações plasmáticas de nitrito dos animais dos grupos Sham e 2R1C. As amostras de plasma foram coletadas $2 \mathrm{~h}$ após o tratamento com enxaguante bucal. Dados mostrados como média \pm S.E.M. ( $n=7$ a 12 por grupo). ${ }^{*} \mathrm{P}<0,05$ versus grupo $2 \mathrm{R} 1 \mathrm{C}+$ Enxaguante 
A

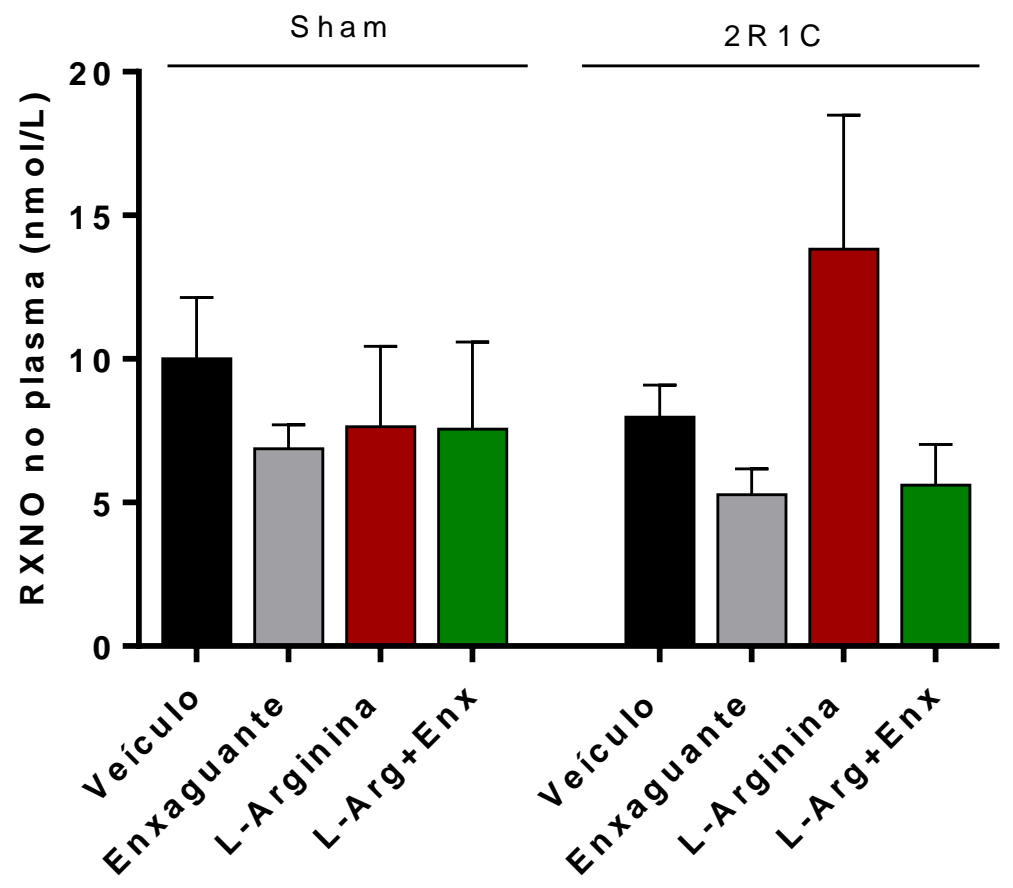

B

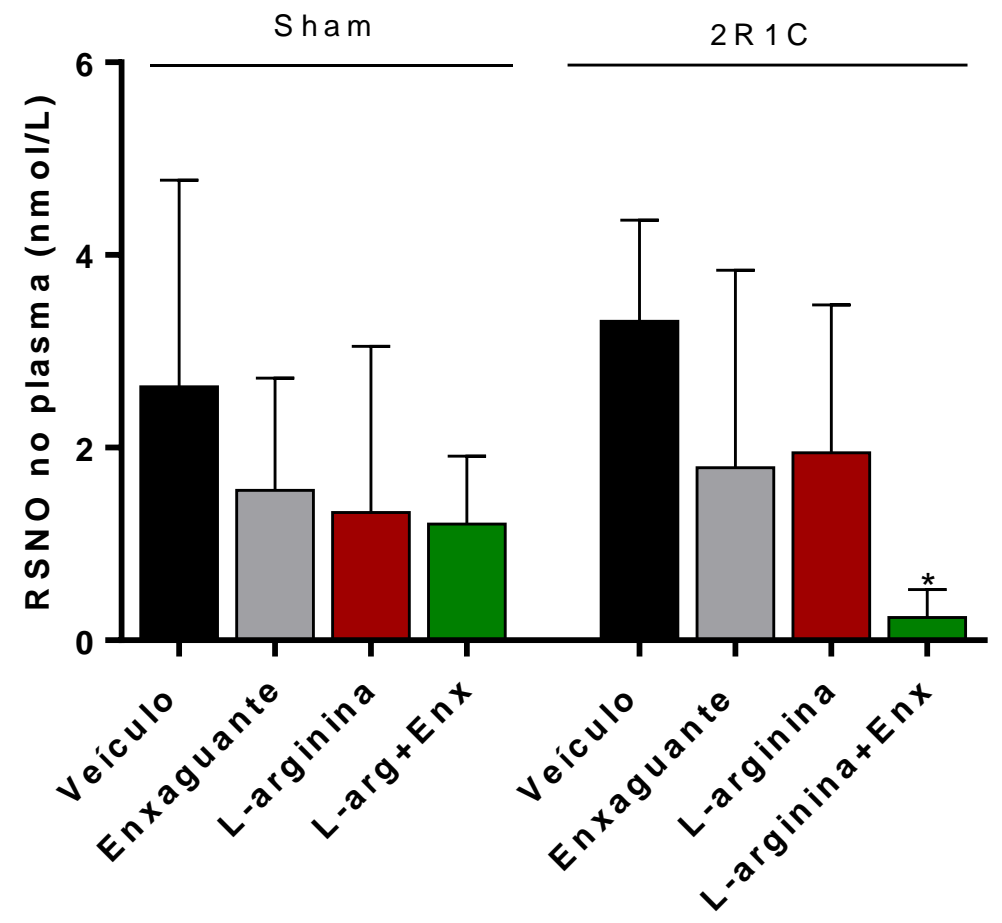

Figura 11. $O$ enxaguante bucal tendeu a diminuir as concentrações plasmáticas de espécies nitrosiladas e nitrosotiois. A figura A mostra as concentrações plasmáticas de espécies nitrosiladas dos animais dos grupos Sham e 2R1C. A figura B mostra as concentrações plasmáticas de nitrosotiois dos animais dos grupos Sham e 2R1C. As amostras de plasma foram coletadas $2 \mathrm{~h}$ após o tratamento com enxaguante bucal. Dados mostrados como média \pm S.E.M. ( $n=4$ a 7 por grupo). ${ }^{*} P<0,05$ versus grupo 2R1C+Veículo. 
5.6. Concentrações teciduais (aorta) de nitrato e nitrito

No que diz respeito às concentrações de nitrito e nitrato na aorta, nos ratos hipertensos, a L-arginina foi capaz de aumentar as concentrações de nitrato e o enxaguante reverteu esse aumento $\left({ }^{*} p<0,05\right.$ em relação ao grupo veículo; $\# p<0,05$ em relação ao grupo L-arginina+Enxaguante com post hoc de Tukey) (Figura 12.A), enquanto as concentrações de nitrito não foram alteradas por nenhum dos tratamentos (Figura 12.B). 
A

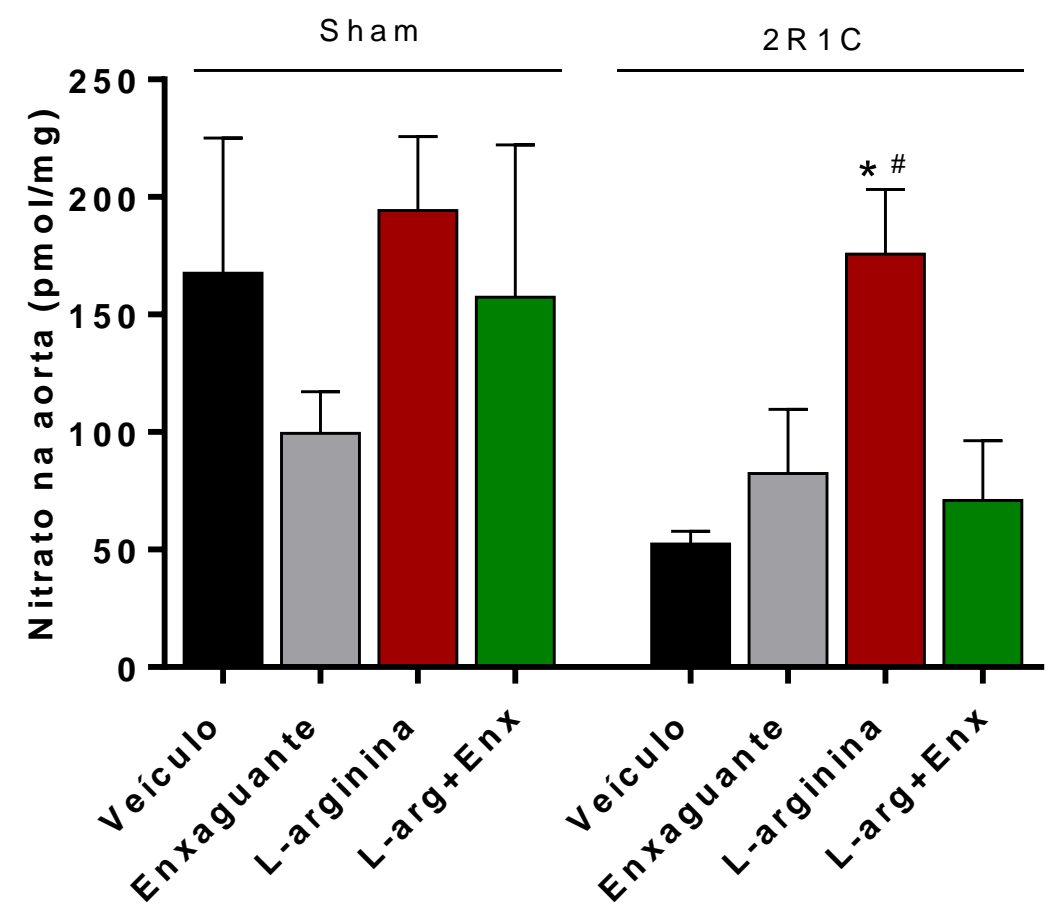

B

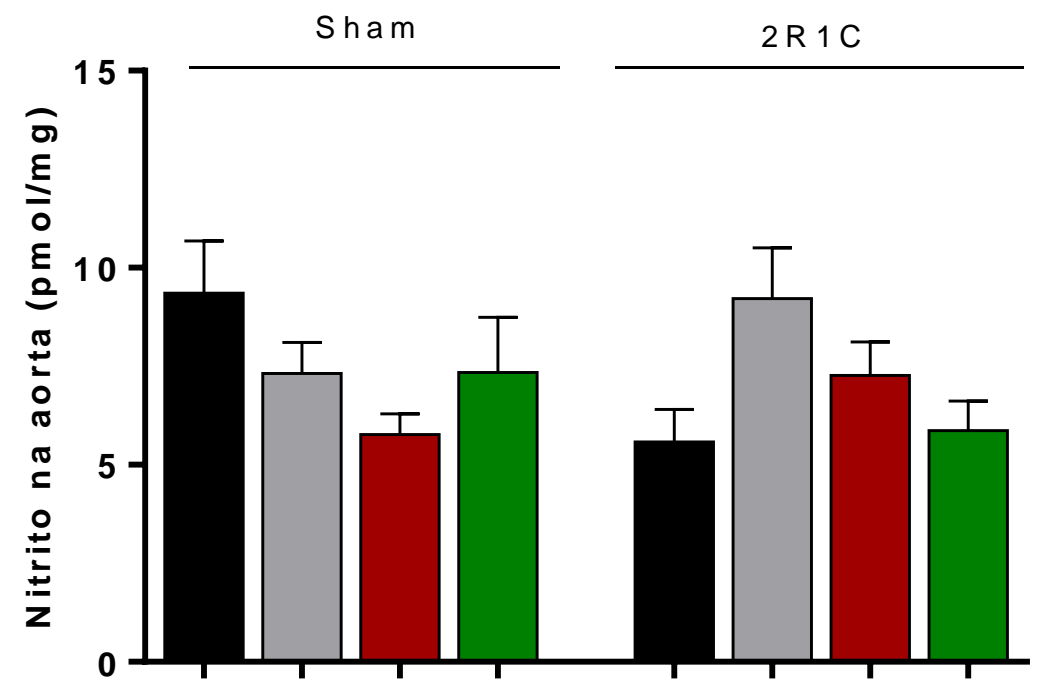

Figura 12: $O$ enxaguante bucal foi capaz de reverter o aumento na concentração de nitrato na aorta ocasionado pela L-arginina nos ratos 2R1C. ( $n=5$ a 8 por grupo). A figura $A$ mostra as concentrações de nitrato na aorta de animais dos grupos Sham e 2R1C. A figura B mostra as concentrações de nitrito na aorta de animais dos grupos Sham e 2R1C. As amostras de plasma foram coletadas $2 \mathrm{~h}$ após o tratamento com enxaguante bucal. Dados mostrados como média \pm S.E.M. ${ }^{*} \mathrm{P}<0,05$ versus grupo $2 \mathrm{R} 1 \mathrm{C}+\mathrm{Veículo}$. $\mathrm{P}<0,05$ versus grupo $2 \mathrm{R} 1 \mathrm{C}+\mathrm{L}$-arginina+Enxaguante. 


\section{DISCUSSÃO}

Apesar de ser conhecidamente o único substrato para a produção de NO, os mecanismos pelos quais a L-arginina exerce seus efeitos anti-hipertensivos ainda não estão totalmente definidos. Além disso, a mesma aparenta exercer tais efeitos apenas em condições específicas, já que em nem todos os estudos encontrados, a L-arginina foi capaz de ocasionar efeitos benéficos na hipertensão (HIGASHI et al., 1995b; LEKAKIS et al., 2002; PANZA et al., 1993). Portanto, é de extrema importância a descoberta de possíveis mecanismos pelos quais a L-arginina poderia trazer benefícios na hipertensão, além de fatores que possam interferir nestes efeitos, já que estes poderiam interferir também na eficácia de outros fármacos anti-hipertensivos capazes de estimular a produção de NO.

O presente estudo mostra que a L-arginina possui efeitos anti-hipertensivos e, consequentemente, de melhora na função vascular no modelo utilizado (2R1C) e que o enxaguante bucal $(\mathrm{CHX})$ é capaz de reverter estes efeitos. Além disso, a L-arginina foi capaz de promover aumento tecidual de um dos metabólitos do NO, o nitrato, e o enxaguante foi capaz de reverter esse aumento. O uso de enxaguante bucal também tendeu a diminuir a concentração plasmática de nitrito, espécies nitros(il)adas e nitrosotiois.

Como esperado, foi detectada uma diminuição na quantidade de bactérias da cavidade oral 2 horas após o uso de enxaguante bucal, resultado também encontrado em outros trabalhos em que os animais e pacientes eram tratados com enxaguante bucal (HAERIAN-ARDAKANI et al., 2015; PINHEIRO; FERREIRA; et al., 2016). A atividade nitrato redutase das bactérias orais também foi estatisticamente menor nos ratos tratados com enxaguante. Nesse sentido, sugere-se que tenha havido uma diminuição da quantidade de bactérias que, conhecidamente, possuem esta atividade, 
como as bactérias do gênero Haemophilus spp e Streptococcus spp (HYDE; LUK; et al., 2014; LUNDBERG, JON O et al., 2004). Já foi observada, inclusive, uma diminuição significativa na quantidade de bactérias do gênero Haemophilus diante da utilização de enxaguante bucal em ratos saudáveis, mesmo diante de um aumento na diversidade das bactérias se comparados com a quantidade basal dos animais (HYDE; LUK; et al., 2014). Portanto, em nosso estudo, a utilização de enxaguante bucal deve ter ocasionado a interrupção do ciclo êntero-salivar do nitrato por diminuir a quantidade de bactérias orais com capacidade nitrato redutase.

Os efeitos benéficos da L-arginina sobre as doenças cardiovasculares se devem não só ao fato de esta ser substrato para a produção de NO, mas também aos efeitos diretos que esta possui, como sua capacidade de agir como um sequestrador de espécies reativas de oxigênio e diminuir a peroxidação lipídica nas células endoteliais (TOUSOULIS, D et al., 2002; WASCHER et al., 1997). A suplementação com L-arginina na hipertensão também pode ser benéfica pelo fato de, nesta patologia, haver um aumento na expressão da arginase, que é responsável pela degradação da L-arginina em seu metabólito, a ornitina (BÖGER; RON, 2005). Esta diminuição da biodisponibilidade de L-arginina culmina na diminuição de NO que é apontada como um possível mecanismo para a disfunção endotelial presente nos modelos animais de hipertensão e na hipertensão essencial em humanos.

Nesse sentido, também já foi demonstrado que, na hipertensão, existe uma diminuição na taxa de transporte de L-arginina nas células sanguíneas (JOHNSON et al., 2015; MOSS et al., 2004). Apesar dos comprovados efeitos anti-hipertensivos da L-arginina exógena, as concentrações celulares de L-arginina já estão acima do que é realmente utilizado para a produção de NO. Este mecanismo é conhecido como o "paradoxo da L-arginina” (WYATT; STEINERT; MANN, 2004). No entanto, um estudo 
sugeriu que apenas a concentração intracelular de L-arginina não deve ser usada como ponto de referência, já que uma vez transportada para o interior da célula, esta não consegue mais acessar a eNOS ligada à membrana. Portanto, segundo este estudo, a L-arginina extracelular seria o principal determinante da produção de NO em células endoteliais (SHIN; MOHAN; FUNG, 2011).

Apesar de, em nosso estudo, a L-arginina ter sido capaz de reduzir a pressão arterial de ratos $2 \mathrm{R} 1 \mathrm{C}$, os resultados em relação a este fato são controversos. $\mathrm{A}$ administração oral de L-arginina por 3 semanas em ratos hipertensos 2R2C na água de beber (1,25 g/L) não foi capaz de causar reduções significativas na pressão arterial (DE LA RIVA et al., 2000), possivelmente pelo fato de este trabalho ter utilizado uma dose inferior ao do presente estudo. Em animais espontaneamente hipertensos (SHR), a suplementação com L-arginina em uma dose de $170 \mathrm{mg} \mathrm{kg}^{-1}$ por gavagem foi capaz de reduzir significativamente a pressão arterial (PIÑEIRO et al., 2010). Tais diferenças nos achados em relação aos efeitos anti-hipertensivos da L-arginina podem ser devido a diferenças metodológicas, principalmente em relação ao modelo de hipertensão utilizado e à dose de L-arginina.

Em nosso estudo, além da diminuição nos valores pressóricos dos ratos hipertensos, a L-arginina também foi capaz de promover melhoras na função vascular destes ratos, deslocando a curva de relaxamento à acetilcolina para a esquerda em relação aos demais grupos hipertensos, além de ter aumentado a potência e o efeito máximo. De maneira interessante, o uso de enxaguante bucal foi capaz de reverter tais efeitos. Um estudo conduzido com pessoas saudáveis demonstrou que uma única dose de L-arginina foi capaz de aumentar a vasodilatação dependente do endotélio (MELIK et al., 2017). A L-arginina também foi capaz de melhorar a função endotelial 
de ratos com insuficiência renal crônica e a disfunção endotelial de pacientes com hipertensão essencial (LEKAKIS et al., 2002; NESHER et al., 2014).

A conversão de nitrato a nitrito por ação das bactérias orais foi, por muitos anos, descrita como danosa já que o nitrito, quando deglutido, pode dar origem às $\mathrm{N}$ nitrosaminas, que são conhecidas por possuir efeitos potencialmente carcinogênicos (SPIEGELHALDER B, EISENBRAND G, 1976). No entanto, estudos recentes mostraram a importância do ciclo êntero-salivar do nitrato e da participação das bactérias orais com atividade nitrato redutase para a manutenção dos efeitos benéficos do nitrato em doenças cardiovasculares como a hipertensão (KAPIL et al., 2018; PINHEIRO; FERREIRA; et al., 2016). Nesse sentido, este ciclo tem sido apontado como uma forma alternativa para a produção de NO (GOVONI et al., 2008; LUNDBERG, JON O.; WEITZBERG; GLADWIN, 2008).

Como dito anteriormente, a utilização de enxaguante bucal tem sido apontada como uma forma de interrupção do ciclo êntero-salivar do nitrato, já que se tem demonstrado que este é capaz de inibir o aumento da concentração de nitrito na saliva e no plasma após administração de nitrato, além de reverter os efeitos antihipertensivos deste (GOVONI et al., 2008; PINHEIRO; FERREIRA; et al., 2016). Outro estudo, conduzido com pacientes homens e mulheres hipertensos tratados demonstrou que o uso de enxaguante bucal duas vezes ao dia, por 3 dias, diminuiu a redução oral de nitrato a nitrito com um aumento concomitante na pressão arterial sistólica (BONDONNO et al., 2015). Neste trabalho, a utilização de enxaguante bucal foi capaz de reverter a ação anti-hipertensiva da L-arginina de maneira semelhante ao que já foi observado com o nitrato em animais. 
Em nosso estudo, a L-arginina foi capaz de aumentar as concentrações de nitrato na aorta de ratos hipertensos, porém, apesar da tendência, não alterou de maneira estatisticamente significativa as concentrações plasmáticas e teciduais de nenhum outro metabólito do NO. Um estudo conduzido em ratos, onde foi administrada a L-citrulina, também um produto da reação de síntese de NO a partir da L-arginina, não foram encontradas alterações nas concentrações dos metabólitos do NO, nitrito e nitrato (NOx) (MCKINLEY-BARNARD et al., 2015). No entanto, em estudos realizados em humanos saudáveis e com anemia falciforme, a administração de L-arginina foi capaz de aumentar as concentrações de NOx (JAJA et al., 2016; MIRMIRAN et al., 2016). Em outro estudo, conduzido com pacientes com doença arterial coronariana, a suplementação com L-arginina foi capaz de reduzir a perda renal de nitrito (SCHNEIDER et al., 2015). De maneira contrastante, em um estudo conduzido com ratos com hipercolesterolemia, não foram encontrados aumentos nos níveis de NOx diante do tratamento com L-arginina, ao contrário, os animais tratados tiveram concentrações significativamente menores se comparados com os não tratados (JAVANMARD; NEMATBAKHSH; MONAJEMI, 2008).

Observa-se, portanto, que as concentrações dos metabólitos de NO diante da suplementação com L-arginina encontradas na literatura variam muito. Isto pode se dever às diferenças étnicas dos trabalhos realizados com humanos e às diferentes espécies nos estudos realizados com animais, além de diferenças metodológicas na quantificação destes metabólitos, na dose de L-arginina administrada e nas condições e patologias a que estes animais estavam sujeitos. $O$ fato de em nosso estudo não terem sido encontrados aumentos estatisticamente significativos em nenhum outro metabólito do NO que não o nitrato, pode se dever ao fato de a administração de Larginina ter sido feita na água de beber e, portanto, não ter sido possível um controle 
do tempo desde a última dose de L-arginina ingerida até a eutanásia do animal, podendo este ter sido um fator de aumento da variabilidade intergrupos.

Nos animais hipertensos, o uso de enxaguante bucal reverteu o aumento tecidual de nitrato ocasionado pela L-arginina e tendeu a diminuir as concentrações plasmáticas de nitrito, espécies nitrosiladas e nitrosotiois em relação aos demais grupos. Outros estudos já demonstraram que o uso de enxaguante bucal é capaz de diminuir as concentrações de metabólitos do NO diante da suplementação com nitrato (MCDONAGH et al., 2015; PINHEIRO; FERREIRA; et al., 2016). De maneira semelhante, em um estudo conduzido com pessoas saudáveis, o uso de enxaguante bucal durante 3 dias foi capaz de aumentar as concentrações salivares de nitrato, ou seja, de diminuir sua conversão a nitrito. Apesar disso, não foram encontradas diferenças significativas nas concentrações plasmáticas de nitrito após a utilização do enxaguante (SUNDQVIST; LUNDBERG; WEITZBERG, 2016).

A utilização de enxaguante bucal, por ser capaz de interromper o ciclo ênterosalivar do nitrato, também poderia ser capaz de diminuir a formação de nitrosotiois no estômago, já que este diminui a quantidade de nitrito e, consequentemente de NO, disponíveis neste local (CARLSTRÖM et al., 2015). Os nitrosotiois são oriundos da reação do NO formado endogenamente com biomoléculas portadoras do grupo $\mathrm{SH}$. Eles podem ser gerados por reação com íons nitrosônio ( $\left.\mathrm{NO}^{+}\right)$formados a partir de complexos de dinitrosil - ferro ou peroxinitrito derivado da reação de NO com superóxido (BOESE et al., 1995; FEELISCH et al., 2002; MORO et al., 1994; VAN DER VLIET et al., 1998). Alternativamente, sob condições anaeróbicas, os RSNOs podem ser formados pela interação direta do NO com tióis na presença de receptores de elétrons (GOW; BUERK; ISCHIROPOULOS, 1997). 
A importância do grupo SNO como uma fonte de modificação pós-traducional é evidenciada pela grande quantidade de estudos que apontam que as proteínas podem ser reguladas por S-nitrosilação de resíduos de cisteína específicos (XU et al., 2019; ZAMORANO et al., 2019). Um estudo recente mostrou que a suplementação com L-arginina poderia reduzir a degradação da proteína muscular e dos déficits de força que ocorrem durante a prática de exercício físico na contração excêntrica, já que a L-arginina pode induzir S-nitrosilação da enzima calpaína-1 (enzima responsável pela proteólise de proteínas-chave, como a Junctofilina e o receptor de diidropiridina), o que resulta em uma regulação negativa da mesma (KANZAKI et al., 2018).

Em nosso estudo, apesar de não terem sido detectados aumentos nos nitrosotiois plasmáticos diante do tratamento com L-arginina, a mesma poderia ser capaz de ocasionar aumento de S-nitrosilação tecidual e, consequentemente, alterações pós-trasducionais em proteínas-chave para a hipertensão. Conjuntamente, em nosso estudo, houve uma tendência de diminuição de RSNO diante do tratamento concomitante de L-arginina e enxaguante bucal, indicando que, possivelmente, a nitrosilação tecidual poderia estar sendo comprometida diante do uso de enxaguante bucal. Um estudo já mostrou que o tratamento com enxaguante bucal foi capaz de diminuir a porcentagem de nitrosilação tecidual de animais hipertensos em relação aos seus grupos controles (PINHEIRO; FERREIRA; et al., 2016). Nesse sentido, apesar de nosso estudo não demonstrar este fato, um possível mecanismo para a reversão dos efeitos anti-hipertensivos da L-arginina ocasionados pelo enxaguante bucal seria a reversão da S-nitrosilação tecidual ocasionada pela L-arginina. 


\section{CONCLUSÃO E CONSIDERAÇÕES FINAIS}

Diante do exposto, podemos concluir que a L-arginina foi capaz de reduzir a pressão arterial e melhorar a função endotelial de ratos hipertensos e o enxaguante foi capaz de reverter estes efeitos. Além disso, a administração concomitante com enxaguante bucal reverteu o aumento do nitrato tecidual (aorta) ocasionado pelo tratamento com L-arginina, além de ter tendido a diminuir as concentrações de nitrito, espécies nitros(il)adas e nitrosotiois no plasma de animais hipertensos. É possível sugerir, portanto, que os efeitos da L-arginina na hipertensão dependam, pelo menos em parte, da conversão de nitrato a nitrito e, posteriormente a NO e espécies relacionadas, já que a utilização de enxaguante bucal, que interfere nesta conversão na cavidade oral, por diminuir a quantidade de bactérias com atividade nitrato redutase, foi capaz de reverter os efeitos benéficos da L-arginina na hipertensão. Portanto, sugere-se que a manutenção do ciclo êntero-salivar do nitrato é determinante para os efeitos exercidos pela L-arginina. No entanto, estudos adicionais precisam ser feitos a fim de elucidar outras possíveis consequências da utilização de enxaguante bucal que podem levar à reversão dos efeitos antihipertensivos da L-arginina. 


\section{REFERÊNCIAS}

AHMED, Khandaker A. et al. Measuring nitrate reductase activity from human and rodent tongues. Nitric Oxide - Biology and Chemistry, v. 66, p. 62-70, 2017.

ALDERTON, W K; COOPER, C E; KNOWLES, R G. Nitric oxide synthases: structure, function and inhibition. The Biochemical journal, v. 357, n. Pt 3, p. 593-615, ago. 2001.

AMARAL, Jefferson $\mathrm{H}$ et al. Consistent antioxidant and antihypertensive effects of oral sodium nitrite in DOCA-salt hypertension. Redox biology, v. 5, p. 340-346, ago. 2015.

ANDREW, Penelope J.; MAYER, Bernd. Enzymatic function of nitric oxide synthases. Cardiovascular Research, v. 43, n. 3, p. 521-531, 1999.

ARTICLE, Review; SHI, Yi; VANHOUTTE, Paul M. Macro- and microvascular endothelial dysfunction in diabetes. Journal of diabetes, v. 9, n. 5, p. 434-449, maio 2017.

ATIK, Fatih et al. Analysis of the Factors Related to the Blood Pressure Control in Hypertension. Journal of the College of Physicians and Surgeons--Pakistan: JCPSP, v. 28, n. 6, p. 423-426, jun. 2018.

BENJAMIN, N et al. Stomach NO synthesis. Nature. England: [s.n.]. , abr. 1994

BJORNE, Hakan; WEITZBERG, Eddie; LUNDBERG, Jon O. Intragastric generation of antimicrobial nitrogen oxides from saliva--physiological and therapeutic considerations. Free radical biology \& medicine, v. 41, n. 9, p. 1404-1412, nov. 2006.

BODE-BOGER, Stefanie M; SCALERA, Fortunato; IGNARRO, Louis J. The L-arginine paradox: Importance of the L-arginine/asymmetrical dimethylarginine ratio. Pharmacology \& therapeutics, v. 114, n. 3, p. 295-306, jun. 2007.

BOESE, M et al. S-nitrosation of serum albumin by dinitrosyl-iron complex. The Journal of biological chemistry, v. 270, n. 49, p. 29244-29249, dez. 1995.

BÖGER, Rainer H; RON, Eyal S. L-Arginine Improves Vascular Function by Overcoming the Deleterious Effects of ADMA, a Novel Cardiovascular Risk Factor. v. 10, n. 1, 2005.

BOGLE, R G et al. Regulation of L-arginine transport and nitric oxide release in superfused porcine aortic endothelial cells. The Journal of physiology, v. 490 ( Pt 1, p. 229-241, jan. 1996.

BONDONNO, Catherine $\mathrm{P}$. et al. Antibacterial mouthwash blunts oral nitrate reduction and increases blood pressure in treated hypertensive men and women. American Journal of Hypertension, v. 28, n. 5, p. 572-575, 2015.

BRASIL. MINISTÉRIO DA SAÚDE. Percepção Do Estado De Saúde, Estilos De Vida E Doenças Crônicas. [S.I: S.n.], 2014. Disponível em: <ftp://ftp.ibge.gov.br/PNS/2013/pns2013.pdf>.

BRIASOULIS, Alexandros; AGARWAL, Vikram; MESSERLI, Franz H. Alcohol 
consumption and the risk of hypertension in men and women: a systematic review and meta-analysis. Journal of clinical hypertension (Greenwich, Conn.), v. 14, n. 11, p. 792-798, nov. 2012.

BRONIOWSKA, Katarzyna A; HOGG, Neil. The chemical biology of S-nitrosothiols. Antioxidants \& redox signaling, v. 17, n. 7, p. 969-980, out. 2012a.

BRONIOWSKA, Katarzyna A; HOGG, Neil. The Chemical Biology of S-Nitrosothiols. v. 17, n. 7, 2012b.

BRYAN, Nathan $\mathrm{S}$ et al. Cellular targets and mechanisms of nitros(yl)ation: an insight into their nature and kinetics in vivo. Proceedings of the National Academy of Sciences of the United States of America, v. 101, n. 12, p. 4308-4313, mar. 2004a.

BRYAN, Nathan $\mathrm{S}$ et al. Cellular targets and mechanisms of nitros(yl)ation: an insight into their nature and kinetics in vivo. Proceedings of the National Academy of Sciences of the United States of America, v. 101, n. 12, p. 4308-4313, 2004b.

BRYAN, Nathan S; IVY, John L. Inorganic nitrite and nitrate: evidence to support consideration as dietary nutrients. Nutrition research (New York, N.Y.), v. 35, n. 8, p. 643-654, ago. 2015.

CARLSTRÖM, Mattias et al. Cross-talk Between Nitrate-Nitrite-NO and NO Synthase Pathways in Control of Vascular NO Homeostasis. Antioxidants \& Redox Signaling, v. 23, n. 4, p. 295-306, 2015. Disponível em: <http://online.liebertpub.com/doi/10.1089/ars.2013.5481>.

CARVALHO MALTA, Deborah et al. Prevalência e fatores associados com hipertensão arterial autorreferida em adultos brasileiros. Rev Saude Publica, v. 51, n. 1, p. 1-11, 2017. Disponível em: $<$ http://www.scielo.br/pdf/rsp/v51s1/pt_0034-8910-rsp-S151887872017051000006.pdf>.

COCKCROFT, John R. Exploring vascular benefits of endothelium-derived nitric oxide. American journal of hypertension, v. 18, n. 12 Pt 2, p. 177S-183S, dez. 2005.

COOKE, J P; DZAU, $V$ J. Nitric oxide synthase: role in the genesis of vascular disease. Annual review of medicine, v. 48, p. 489-509, 1997.

COOKE, John $P$. et al. Antiatherogenic effects of L-arginine in the hypercholesterolemic rabbit. Journal of Clinical Investigation, v. 90, n. 3, p. 1168-1172, 1992.

COSBY, Kenyatta et al. Nitrite reduction to nitric oxide by deoxyhemoglobin vasodilates the human circulation. Nature medicine, v. 9, n. 12, p. 1498-1505, dez. 2003.

CYLWIK, Dorota; MOGIELNICKI, Andrzej; BUCZKO, Włodzimierz. L-arginine and cardiovascular system. Pharmacological Reports, v. 57, n. 1, p. 14-22, 2005.

DE LA RIVA, I $\mathrm{J}$ et al. Effect of oral L-arginine administration for three weeks in two kidney-two clip hypertensive rats. Archives of Physiology and Biochemistry, v. 108, n. 5, p. 415-421, 2000.

DEVES, R; BOYD, C A. Transporters for cationic amino acids in animal cells: 
discovery, structure, and function. Physiological reviews, v. 78, n. 2, p. 487545, abr. 1998.

DUNCAN, Callum et al. Chemical generation of nitric oxide in the mouth from the enterosalivary circulation of dietary nitrate. Nature Medicine, v. 1, n. 6, p. 546$551,1995$.

FAASSEN, Ernst E Van et al. NIH Public Access. v. 29, n. 5, p. 683-741, 2010.

FEELISCH, Martin et al. Concomitant S-, N-, and heme-nitros(yl)ation in biological tissues and fluids: implications for the fate of NO in vivo. FASEB journal : official publication of the Federation of American Societies for Experimental Biology, v. 16, n. 13, p. 1775-1785, nov. 2002. Disponível em: <http://www.fasebj.org/doi/10.1096/fj.02-0363com>.

FLEMING, I; BUSSE, R. Signal transduction of eNOS activation. Cardiovascular research, v. 43, n. 3, p. 532-541, ago. 1999.

FRANCIS, Sharron $\mathrm{H}$ et al. CGMP-dependent protein kinases and cGMP phosphodiesterases in nitric oxide and cGMP action. Pharmacological reviews, v. 62 , n. 3, p. 525-563, set. 2010.

FURCHGOTT, R F; ZAWADZKI, J V. The obligatory role of endothelial cells in the relaxation of arterial smooth muscle by acetylcholine. Nature, v. 288, n. 5789, p. 373-376, nov. 1980.

GALLEY, H F; WEBSTER, N R. Physiology of the endothelium. British Journal of Anaesthesia, v. 93, n. 1, p. 105-113, 2004. Disponível em: $<$ http://dx.doi.org/10.1093/bja/aeh163>.

GHOSH, Arijit et al. Role of free fatty acids in endothelial dysfunction. Journal of biomedical science, v. 24, n. 1, p. 50, jul. 2017.

GHOSH, Dipak K; SALERNO, J C. Nitric oxide synthases: domain structure and alignment in enzyme function and control. Frontiers in bioscience : a journal and virtual library, v. 8, p. d193-209, jan. 2003.

$\mathrm{GHOSH}$, Suborno $\mathrm{M}$ et al. Enhanced vasodilator activity of nitrite in hypertension: critical role for erythrocytic xanthine oxidoreductase and translational potential. Hypertension (Dallas, Tex. : 1979), v. 61, n. 5, p. 1091-1102, maio 2013.

GOUVÊA, S. A. et al. Oral administration of L-arginine decreases blood pressure and increases renal excretion of sodium and water in renovascular hypertensive rats. Brazilian Journal of Medical and Biological Research, v. 36, n. 7, p. 943949, 2003.

GOUVEA, Sonia Alves et al. Role of renal nerves in the treatment of renovascular hypertensive rats with $\mathrm{L}$-arginine. International Journal of Hypertension, $\mathrm{v}$. 2014, p. 735627, 2014.

GOVONI, Mirco et al. The increase in plasma nitrite after a dietary nitrate load is markedly attenuated by an antibacterial mouthwash. Nitric Oxide - Biology and Chemistry, v. 19, n. 4, p. 333-337, dez. 2008.

GOW, A J; BUERK, D G; ISCHIROPOULOS, H. A novel reaction mechanism for the formation of S-nitrosothiol in vivo. The Journal of biological chemistry, v. 272, n. 
5, p. 2841-2845, jan. 1997.

HABERMEYER, Michael et al. Nitrate and nitrite in the diet: how to assess their benefit and risk for human health. Molecular nutrition \& food research, v. 59, n. 1, p. 106-128, jan. 2015.

HAERIAN-ARDAKANI, Ahmad et al. Comparison of Antimicrobial Effects of Three Different Mouthwashes. v. 44, n. 7, p. 997-1003, 2015.

HIGASHI, Y et al. Effects of L-arginine infusion on renal hemodynamics in patients with mild essential hypertension. Hypertension, v. 25, n. 4 Pt 2, p. 898-902, 1995 a. Disponível em: <http:/www.ncbi.nlm.nih.gov/pubmed/7721451>.

HIGASHI, Y et al. Effects of L-arginine infusion on renal hemodynamics in patients with mild essential hypertension. Hypertension, v. 25, n. 4 Pt 2, p. 898-902, abr. 1995b. Disponível em: <http://www.ncbi.nlm.nih.gov/pubmed/7721451>.

HUANG, Paul L. et al. Hypertension in mice lacking the gene for endothelial nitric oxide synthase. Nature. [S.I: s.n.]. , 1995

HYDE, Embriette R.; LUK, Berkley; et al. Characterization of the rat oral microbiome and the effects of dietary nitrate. Free Radical Biology and Medicine, v. 77, p. 249-257, $2014 . \quad$ Disponível em: <http://dx.doi.org/10.1016/j.freeradbiomed.2014.09.017>.

HYDE, Embriette R; ANDRADE, Fernando; et al. Metagenomic analysis of nitratereducing bacteria in the oral cavity: implications for nitric oxide homeostasis. PloS one, v. 9, n. 3, p. e88645, 2014.

IGNARRO, $\mathrm{L} \mathrm{J}$ et al. Endothelium-derived relaxing factor produced and released from artery and vein is nitric oxide. Proceedings of the National Academy of Sciences of the United States of America, v. 84, n. 24, p. 9265-9269, dez. 1987.

JAJA, S. I. et al. Supplementation with I-arginine stabilizes plasma arginine and nitric oxide metabolites, suppresses elevated liver enzymes and peroxidation in sickle cell anaemia. Pathophysiology, v. 23, n. 2, p. 81-85, jun. 2016.

JANSSON, Emmelie $\AA$ et al. A mammalian functional nitrate reductase that regulates nitrite and nitric oxide homeostasis. Nature Chemical Biology, v. 4, n. 7, p. 411417, 2008.

JAVANMARD, Shaghayegh Haghjooy; NEMATBAKHSH, Mehdi; MONAJEMI, Alireza. L-Arginine supplementation influenced nitrite but not nitrate and total nitrite in rabbit model of hypercholesterolemia. Iranian Biomedical Journal, v. 12, n. 3, p. 179-184, jul. 2008.

$\mathrm{JJ}$, Doel et al. Evaluation of bacterial nitrate reduction in the human oral cavity. European journal of oral sciences, v. 113, n. 1, p. 14-19, fev. 2005.

JOHNSON, Fruzsina $\mathrm{K}$ et al. Arginase promotes endothelial dysfunction and hypertension in obese rats. Obesity (Silver Spring, Md.), v. 23, n. 2, p. 383-390, fev. 2015.

KANZAKI, Keita et al. I-arginine ingestion inhibits eccentric contraction-induced proteolysis and force deficit via S-nitrosylation of calpain. Physiological reports, v. 6, n. 2, jan. 2018. 
KAPIL, Vikas et al. Physiological role for nitrate-reducing oral bacteria in blood pressure control. Free Radical Biology and Medicine. [S.I: s.n.]. Disponível em: <http://ac.els-cdn.com/S0891584912018229/1-s2.0-S0891584912018229main.pdf? tid=ce7035d8-6c1f-11e4-a1e100000aacb35e\&acdnat=1415984639_894eb263dddd59d44ee9dfb8fb2cb838> . , 2013a

KAPIL, Vikas et al. Physiological role for nitrate-reducing oral bacteria in blood pressure control. Free Radical Biology and Medicine, v. 55, p. 93-100, 2013b. Disponível em: <http://dx.doi.org/10.1016/j.freeradbiomed.2012.11.013>.

KAPIL, Vikas et al. Sex differences in the nitrate-nitrite-NO(*) pathway: Role of oral nitrate-reducing bacteria. Free radical biology \& medicine, v. 126, p. 113-121, out. 2018.

KIMURA, Lilian et al. Genomic ancestry of rural African-derived populations from Southeastern Brazil. American journal of human biology: the official journal of the Human Biology Council, v. 25, n. 1, p. 35-41, 2013.

LAUER, $T$ et al. Plasma nitrite rather than nitrate reflects regional endothelial nitric oxide synthase activity but lacks intrinsic vasodilator action. Proceedings of the National Academy of Sciences of the United States of America, v. 98, n. 22, p. 12814-12819, out. 2001.

LECLERC, Patrice $\mathrm{C}$ et al. S-nitrosylation of cysteine 289 of the AT1 receptor decreases its binding affinity for angiotensin II. British journal of pharmacology, v. 148 , n. 3, p. 306-313, jun. 2006.

LEE, Tony J F; YU, Jun-Ge. L-Citrulline recycle for synthesis of $\mathrm{NO}$ in cerebral perivascular nerves and endothelial cells. Annals of the New York Academy of Sciences, v. 962, p. 73-80, maio 2002.

LEKAKIS, John P. et al. Oral L-arginine improves endothelial dysfunction in patients with essential hypertension. International Journal of Cardiology, v. 86, n. 2-3, p. 317-323, 2002.

LI, Huiying; POULOS, Thomas L. Structure-function studies on nitric oxide synthases. Journal of inorganic biochemistry, v. 99, n. 1, p. 293-305, jan. 2005.

LI, Li Qiang et al. Establishment and evaluation of a reversible two-kidney, one-clip renovascular hypertensive rat model. Experimental and Therapeutic Medicine, v. 13, n. 6, p. 3291-3296, 2017.

LIU, Xiaohong et al. Asymmetric dimethylarginine (ADMA) as an important risk factor for the increased cardiovascular diseases and heart failure in chronic kidney disease. Nitric oxide : biology and chemistry, v. 78, p. 113-120, jun. 2018.

LUNDBERG, J O et al. Intragastric nitric oxide production in humans: measurements in expelled air. Gut, v. 35, n. 11, p. 1543-1546, nov. 1994.

LUNDBERG, Jon O. et al. Nitrate, bacteria and human health. Nature Reviews Microbiology, v. 2, n. 7, p. 593-602, 2004.

LUNDBERG, Jon O.; WEITZBERG, Eddie; GLADWIN, Mark T. The nitrate-nitrite-nitric oxide pathway in physiology and therapeutics. Nature Reviews Drug Discovery, 


$$
\text { v. 7, n. 2, p. 156-167, } 2008 .
$$

LUNDBERG, Jon $O$ et al. Nitrate, bacteria and human health. Nature reviews. Microbiology, v. 2, n. 7, p. 593-602, jul. 2004.

LUNDBERG, Jon O; WEITZBERG, Eddie. NO-synthase independent NO generation in mammals. Biochemical and biophysical research communications, v. 396, $\mathrm{n}$. 1, p. 39-45, maio 2010.

LUNDBERG, Jon O; WEITZBERG, Eddie. NO generation from nitrite and its role in vascular control. Arteriosclerosis, thrombosis, and vascular biology, v. 25, n. 5, p. 915-922, maio 2005.

LUNDBERG, Jon O; WEITZBERG, Eddie; GLADWIN, Mark T. The nitrate-nitrite-nitric oxide pathway in physiology and therapeutics. Nature reviews. Drug discovery, v. 7 , n. 2, p. 156-167, fev. 2008.

MACALLISTER, R $\mathrm{J}$ et al. Metabolism of methylarginines by human vasculature; implications for the regulation of nitric oxide synthesis. British journal of pharmacology, v. 112, n. 1, p. 43-48, maio 1994.

MALACHIAS, MVB et al . 7aㅡ Diretriz Brasileira de Hipertensão Arterial: Capítulo 3 Avaliação Clínica e Complementar. Arq. Bras. Cardiol., São Paulo, v. 107, n. 3, supl. 3, p. 14-17, sept. 2016. Disponível em: http://publicacoes.cardiol.br/2014/diretrizes/2016/05_HIPERTENSAO_ARTER IAL.pdf. Acesso em: dez. 2018.

MARTÍNEZ-RUIZ, Antonio; LAMAS, Santiago. Signalling by NO-induced protein Snitrosylation and S-glutathionylation: Convergences and divergences. v. 75, p. 220-228, 2007.

MCDONAGH, S T J et al. The Effects of Chronic Nitrate Supplementation and the Use of Strong and Weak Antibacterial Agents on Plasma Nitrite Concentration and Exercise Blood Pressure. International journal of sports medicine, v. 36, n. 14, p. 1177-1185, dez. 2015.

MCKINLEY-BARNARD, Sarah et al. Combined L-citrulline and glutathione supplementation increases the concentration of markers indicative of nitric oxide synthesis. Journal of the International Society of Sports Nutrition, v. 12, n. 1, p. 1-8, 2015. Disponível em: <http://dx.doi.org/10.1186/s12970-015-0086-7>.

MELIK, Ziva et al. L-arginine as dietary supplement for improving microvascular function. Clinical Hemorheology and Microcirculation, v. 65, n. 3, p. 205-217, 2017.

MIRMIRAN, Parvin et al. The association of dietary L-arginine intake and serum nitric oxide metabolites in adults: A population-based study. Nutrients, v. 8, n. 5, p. 1-13, 2016.

MONCADA, S; PALMER, R M; HIGGS, E A. Nitric oxide: physiology, pathophysiology, and pharmacology. Pharmacological reviews, v. 43, n. 2, p. 109-142, jun. 1991.

MONTENEGRO, Marcelo $\mathrm{F}$ et al. Sodium nitrite downregulates vascular NADPH oxidase and exerts antihypertensive effects in hypertension. Free radical biology \& medicine, v. 51, n. 1, p. 144-152, jul. 2011. 
MORO, M A et al. Paradoxical fate and biological action of peroxynitrite on human platelets. Proceedings of the National Academy of Sciences of the United States of America, v. 91, n. 14, p. 6702-6706, jul. 1994.

MOSS, Monique B et al. Diminished L-arginine bioavailability in hypertension. Clinical science (London, England: 1979), v. 107, n. 4, p. 391-397, 2004.

MUELLER, Cornelius $\mathrm{F} \mathrm{H}$ et al. ATVB in focus: redox mechanisms in blood vessels. Arteriosclerosis, thrombosis, and vascular biology, v. 25, n. 2, p. 274-278, fev. 2005.

NAGASSAKI, Sabrina et al. eNOS gene T-786C polymorphism modulates atorvastatin-induced increase in blood nitrite. Free radical biology \& medicine, v. 41, n. 7, p. 1044-1049, out. 2006.

NESHER, Nachum et al. L-Arginine improves endothelial function, independently of arginine uptake, in aortas from chronic renal failure female rats. AJP: Renal Physiology, v. 306, n. 4, p. F449-F456, 2014. Disponível em: <http://ajprenal.physiology.org/cgi/doi/10.1152/ajprenal.00457.2013>.

OESS, Stefanie et al. Subcellular targeting and trafficking of nitric oxide synthases. The Biochemical journal, v. 396, n. 3, p. 401-409, jun. 2006.

OLIVEIRA-PAULA, Gustavo $\mathrm{H}$ et al. Tempol improves xanthine oxidoreductasemediated vascular responses to nitrite in experimental renovascular hypertension. Redox biology, v. 8, p. 398-406, ago. 2016.

OLIVEIRA-PAULA, Gustavo H; TANUS-SANTOS, Jose E. Nitrite-stimulated Gastric Formation of S-nitrosothiols As An Antihyper- tensive Therapeutic Strategy. 2018.

ORTIZ DE MONTELLANO, $\mathrm{P} R$ et al. Nitric oxide synthase structure and electron transfer. Drug metabolism and disposition: the biological fate of chemicals, $\mathrm{v}$. 26, n. 12, p. 1185-1189, dez. 1998.

PALMER, R M; ASHTON, D S; MONCADA, S. Vascular endothelial cells synthesize nitric oxide from L-arginine. Nature, v. 333, n. 6174, p. 664-666, jun. 1988.

PALMER, R M; FERRIGE, A G; MONCADA, S. Nitric oxide release accounts for the biological activity of endothelium-derived relaxing factor. Nature, v. 327, n. 6122, p. 524-526, jun. 1987.

PANZA, J A et al. Effect of increased availability of endothelium-derived nitric oxide precursor on endothelium-dependent vascular relaxation in normal subjects and in patients with essential hypertension. Circulation, v. 87, n. 5, p. 1475-1481, maio 1993.

PERTICONE, Francesco et al. Asymmetric dimethylarginine, L-arginine, and endothelial dysfunction in essential hypertension. Journal of the American College of Cardiology, v. 46, n. 3, p. 518-523, ago. 2005.

PETERSSON, Joel et al. Gastroprotective and blood pressure lowering effects of dietary nitrate are abolished by an antiseptic mouthwash. Free Radical Biology and Medicine, v. 46, n. 8, p. 1068-1075, 2009. Disponível em: <http://dx.doi.org/10.1016/j.freeradbiomed.2009.01.011>. 
PIATTI, Pier Marco et al. Acute intravenous L-arginine infusion decreases endothelin1 levels and improves endothelial function in patients with angina pectoris and normal coronary arteriograms: Correlation with asymmetric dimethylarginine levels. Circulation, v. 107, n. 3, p. 429-436, 2003.

PIÑEIRO, Verónica et al. Effect of L-arginine oral supplementation on response to myocardial infarction in hypercholesterolemic and hypertensive rats. Plant Foods for Human Nutrition, v. 65, n. 1, p. 31-37, mar. 2010.

PINHEIRO, Lucas C.; OLIVEIRA-PAULA, Gustavo H.; et al. Omeprazole impairs vascular redox biology and causes xanthine oxidoreductase-mediated endothelial dysfunction. Redox Biology, v. 9, p. 134-143, 2016. Disponível em: $<$ http://dx.doi.org/10.1016/j.redox.2016.08.001>.

PINHEIRO, Lucas C.; FERREIRA, Graziele C.; et al. Oral nitrite circumvents antiseptic mouthwash-induced disruption of enterosalivary circuit of nitrate and promotes nitrosation and blood pressure lowering effect. Free Radical Biology and Medicine, v. 101, n. October, p. 226-235, 2016.

PINHEIRO, Lucas $\mathrm{C}$ et al. Free Radical Biology and Medicine Increase in gastric $\mathrm{pH}$ reduces hypotensive effect of oral sodium nitrite in rats. Free Radical Biology and Medicine, v. 53, n. 4, p. 701-709, 2012. Disponível em: $<$ http://dx.doi.org/10.1016/j.freeradbiomed.2012.06.001>.

PINHEIRO, Lucas $\mathrm{C}$ et al. Gastric S-nitrosothiol formation drives the antihypertensive effects of oral sodium nitrite and nitrate in a rat model of renovascular hypertension. Free radical biology \& medicine, v. 87, p. 252-262, out. 2015.

RAPOPORT, R M; MURAD, F. Agonist-induced endothelium-dependent relaxation in rat thoracic aorta may be mediated through cGMP. Circulation research, v. 52, n. 3, p. 352-357, mar. 1983.

RAVAROTTO, Verdiana et al. Oxidative stress - chronic kidney disease cardiovascular disease: A vicious circle. Life sciences, v. 210, p. 125-131, out. 2018.

SAFFARI, Fereshteh et al. The Effects of Chlorhexidine and Persica Mouthwashes on Colonization of Streptococcus mutans on Fixed Orthodontics O-rings. Journal of dentistry (Shiraz, Iran), v. 16, n. 1, p. 54-57, mar. 2015.

SANTUZZI, C. $\mathrm{H}$. et al. Combined aliskiren and l-arginine treatment has antihypertensive effects and prevents vascular endothelial dysfunction in a model of renovascular hypertension. Brazilian Journal of Medical and Biological Research, v. 48, n. 1, p. 65-76, 2015.

SCHNEIDER, Jessica Y. et al. Effects of chronic oral l-arginine administration on the I-arginine/NO pathway in patients with peripheral arterial occlusive disease or coronary artery disease: I-Arginine prevents renal loss of nitrite, the major NO reservoir. Amino Acids, v. 47, n. 9, p. 1961-1974, 2015.

SELEMIDIS, Stavros et al. Nitric oxide suppresses NADPH oxidase-dependent superoxide production by $\mathrm{S}$-nitrosylation in human endothelial cells. Cardiovascular research, v. 75, n. 2, p. 349-358, jul. 2007.

SESSA, William $C$ et al. Nitric oxide synthases: regulation and function. European 
heart journal, v. 33, n. 7, p. 829-37, 837a-837d, abr. 2012.

SHIN, Soyoung; MOHAN, Srinidi; FUNG, Ho Leung. Intracellular I-arginine concentration does not determine NO production in endothelial cells: Implications on the "I-arginine paradox". Biochemical and Biophysical Research Communications, v. 414, n. 4, p. 660-663, nov. 2011.

SPIEGELHALDER B, EISENBRAND G, Preussmann R. Influence of dietary nitrate on nitrite content of human saliva: possible relevance to in vivo formation of $\mathrm{N}$ nitroso compounds. Food Cosmet Toxicol., v. 14, n. 6, p. 545-8, 1976.

STUEHR, D J. Structure-function aspects in the nitric oxide synthases. Annual review of pharmacology and toxicology, v. 37, p. 339-359, 1997.

STUEHR, Dennis J. Arginine metabolism: enzymology, nutrition, and clinical significance. Proceedings of a symposium dedicated to the memory of Vernon R. Young. April 5-6, 2004. Bermuda. The Journal of nutrition. United States: [s.n.]. Disponível em: <http://www.ncbi.nlm.nih.gov/pubmed/15465777>. , out. 2004

SUNDQVIST, Michaela L.; LUNDBERG, Jon O.; WEITZBERG, Eddie. Effects of antiseptic mouthwash on resting metabolic rate: A randomized, double-blind, crossover study. Nitric Oxide - Biology and Chemistry, v. 61, p. 38-44, 2016. Disponível em: <http://dx.doi.org/10.1016/j.niox.2016.10.003>.

SURKS, $\mathrm{H} \mathrm{K}$ et al. Regulation of myosin phosphatase by a specific interaction with cGMP- dependent protein kinase lalpha. Science (New York, N.Y.), v. 286, n. 5444, p. 1583-1587, nov. 1999.

TANG, Yaoping; JIANG, Hong; BRYAN, Nathan S. Nitrite and nitrate: cardiovascular risk-benefit and metabolic effect. Current opinion in lipidology, v. 22, n. 1, p. 1115, fev. 2011.

TAYLOR, Benjamin et al. Alcohol and hypertension: gender differences in doseresponse relationships determined through systematic review and metaanalysis. Addiction (Abingdon, England), v. 104, n. 12, p. 1981-1990, dez. 2009.

TORRENTS, $\mathrm{D}$ et al. Identification and characterization of a membrane protein $(\mathrm{y}+\mathrm{L}$ amino acid transporter-1) that associates with 4F2hc to encode the amino acid transport activity $\mathrm{y}+\mathrm{L}$. A candidate gene for lysinuric protein intolerance. The Journal of biological chemistry, v. 273, n. 49, p. 32437-32445, dez. 1998.

TOUSOULIS, D et al. L-arginine in cardiovascular disease: dream or reality? - PubMed - NCBI. Vascular Medicine, p. 203-11, 2002. Disponível em: <http://www.ncbi.nlm.nih.gov/pubmed/12553744>.

TOUSOULIS, Dimitris et al. The Role of Nitric Oxide on Endothelial Function. p. 4-18, 2012.

VAN DER VLIET, A et al. Formation of S-nitrosothiols via direct nucleophilic nitrosation of thiols by peroxynitrite with elimination of hydrogen peroxide. The Journal of biological chemistry, v. 273, n. 46, p. 30255-30262, nov. 1998.

WALFORD, G; LOSCALZO, J. Nitric oxide in vascular biology. Journal of thrombosis 
and haemostasis: JTH, v. 1, n. 10, p. 2112-2118, out. 2003.

WARD, F W; COATES, M E; WALKER, R. Nitrate reduction in germfree rats. Progress in clinical and biological research, v. 181, p. 123-125, 1985.

WASCHER, Thomas C. et al. Vascular effects of L-arginine: Anything beyond a substrate for the NO-synthase? Biochemical and Biophysical Research Communications, v. 234, n. 1, p. 35-38, 1997.

WEITZBERG, E; LUNDBERG, J O. Nonenzymatic nitric oxide production in humans. Nitric oxide : biology and chemistry, v. 2, n. 1, p. 1-7, 1998.

WHELTON, Paul $\mathrm{K}$ et al. Guideline for the Prevention, Detection, Evaluation, and Management of High Blood Pressure in Adults. Journal of the American College of Cardiology, v. 71, n. 19, p. e127 LP-e248, 15 maio 2018. Disponível em: $<$ http://www.onlinejacc.org/content/71/19/e127.abstract>.

WINK, D A et al. Reaction kinetics for nitrosation of cysteine and glutathione in aerobic nitric oxide solutions at neutral $\mathrm{pH}$. Insights into the fate and physiological effects of intermediates generated in the NO/O2 reaction. Chemical research in toxicology, v. 7, n. 4, p. 519-525, 1994.

WORLD HEALTH ORGANIZATION. A global brief of hypertension. Geneva, 2013.

WYATT, Amanda W; STEINERT, Joern R; MANN, Giovanni E. Modulation of the Larginine/nitric oxide signalling pathway in vascular endothelial cells. Biochemical Society symposium, v. 156, n. 71, p. 143-156, 2004.

$\mathrm{XU}$, Xiaohui et al. The protein S-nitrosylation of splicing and translational machinery in vascular endothelial cells is susceptible to oxidative stress induced by oxidized low-density lipoprotein. Journal of proteomics, jan. 2019.

YANG, Ying et al. Safety of long-term dietary supplementation with l-arginine in rats. Amino Acids, v. 47, n. 9, p. 1909-1920, 2015.

ZAMORANO, Patricia et al. Galectin-8 induces endothelial hyperpermeability through the eNOS pathway involving S-nitrosylation-mediated adherens junction disassembly. Carcinogenesis, jan. 2019.

ZETTERQUIST, W. et al. Salivary contribution to exhaled nitric oxide. European Respiratory Journal, v. 13, n. 2, p. 327-333, 1999.

ZHANG, Hai-na et al. Endothelial dysfunction in diabetes and hypertension : Role of microRNAs and long non-coding RNAs. Life Sciences, v. 213, n. October, p. 258-268, 2018. Disponível em: <https://doi.org/10.1016/j.lfs.2018.10.028>. 